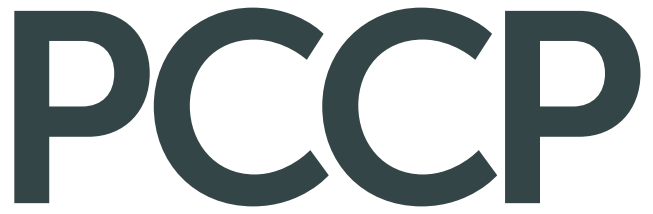

Physical Chemistry Chemical Physics www.rsc.org/pccp

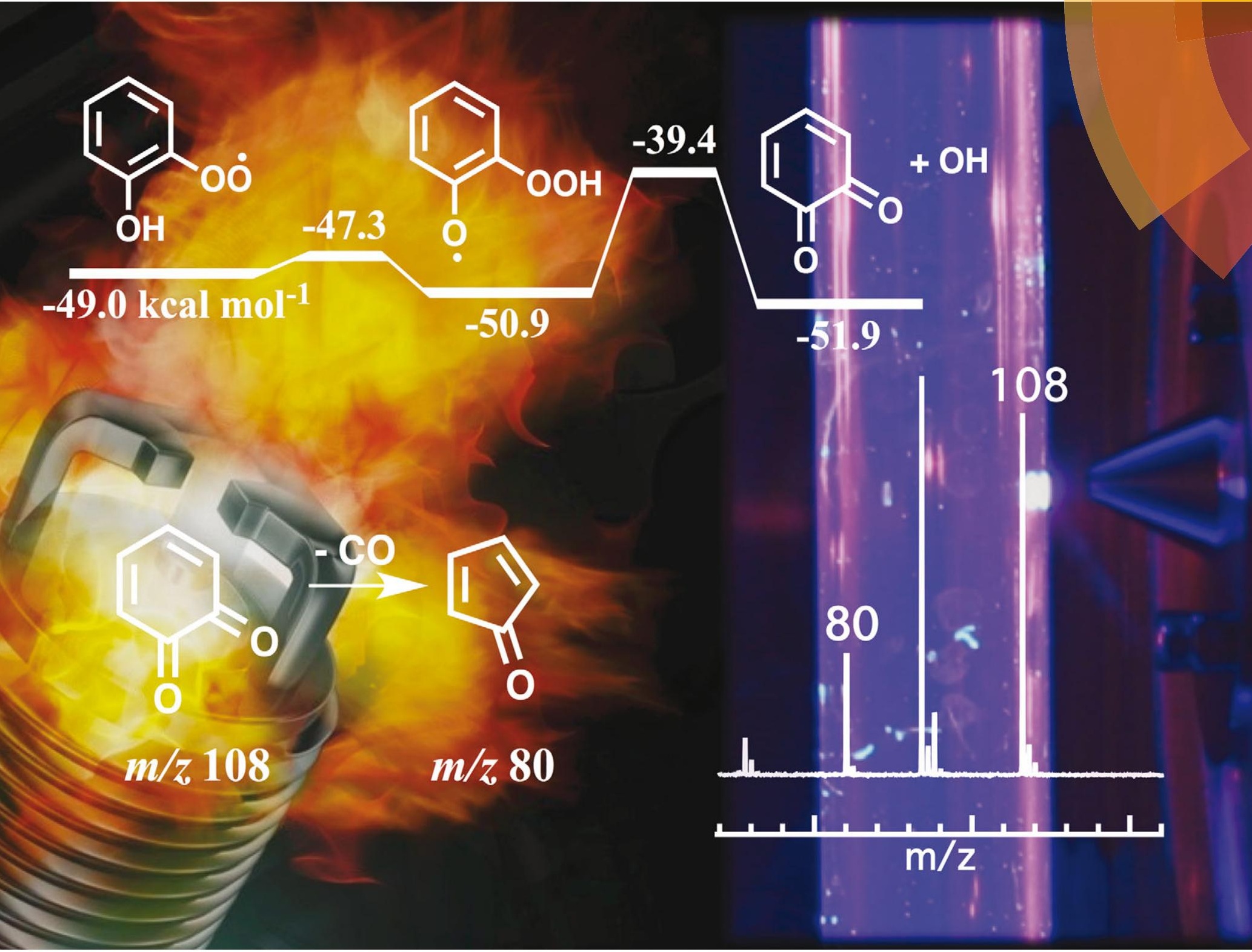

ISSN 1463-9076

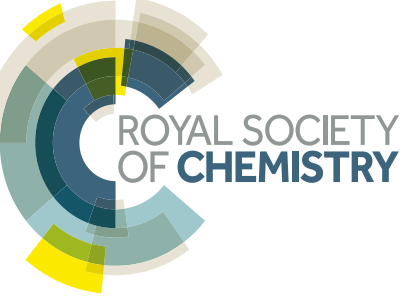




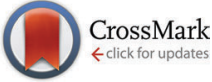

Cite this: Phys. Chem. Chem. Phys., 2016, 18, 4320 Accepted 12th October 2015

DOI: $10.1039 / c 5 c p 02953 h$

www.rsc.org/pccp
Received 22nd May 2015,

\section{Formation and stability of gas-phase o-benzoquinone from oxidation of ortho- hydroxyphenyl: a combined neutral and distonic radical study $\dagger$}

\author{
Matthew B. Prendergast, ${ }^{a}$ Benjamin B. Kirk, ${ }^{b}$ John D. Savee, ${ }^{c}$ David L. Osborn, ${ }^{c}$ \\ Craig A. Taatjes, ${ }^{c}$ Kye-Simeon Masters, ${ }^{d}$ Stephen J. Blanksby, ${ }^{e}$ Gabriel da Silva ${ }^{\dagger}$ and
} Adam J. Trevitt*a

\begin{abstract}
Gas-phase product detection studies of o-hydroxyphenyl radical and $\mathrm{O}_{2}$ are reported at 373,500, and $600 \mathrm{~K}$, at 4 Torr $(533.3 \mathrm{~Pa})$, using VUV time-resolved synchrotron photoionisation mass spectrometry. The dominant products are assigned as o-benzoquinone $\left(\mathrm{C}_{6} \mathrm{H}_{4} \mathrm{O}_{2}, \mathrm{~m} / \mathrm{z}\right.$ 108) and cyclopentadienone $\left(\mathrm{C}_{5} \mathrm{H}_{4} \mathrm{O}, \mathrm{m} / \mathrm{z} 80\right)$. It is concluded that cyclopentadienone forms as a secondary product from prompt decomposition of $O$-benzoquinone (and dissociative ionization of $O$-benzoquinone may contribute to the $\mathrm{m} / \mathrm{z} 80$ signal at photon energies $z 9.8 \mathrm{eV}$ ). Ion-trap reactions of the distonic o-hydroxyphenyl analogue, the 5-ammonium-2-hydroxyphenyl radical cation, with $\mathrm{O}_{2}$ are also reported and concur with the assignment of $\mathrm{o}$-benzoquinone as the dominant product. The ion-trap study also provides support for a mechanism where cyclopentadienone is produced by decarbonylation of $o$-benzoquinone. Kinetic studies compare oxidation of the ammonium-tagged o-hydroxyphenyl and o-methylphenyl radical cations along with trimethylammonium-tagged analogues. Reaction efficiencies are found to be ca. $5 \%$ for both charge-tagged o-hydroxyphenyl and o-methylphenyl radicals irrespective of the charged substituent. G3X-K quantum chemical calculations are deployed to rationalise experimental results for o-hydroxyphenyl $+\mathrm{O}_{2}$ and its charge-tagged counterpart. The prevailing reaction mechanism, after $\mathrm{O}_{2}$ addition, involves a facile 1,5- $\mathrm{H}$ shift in the peroxyl radical and subsequent elimination of $\mathrm{OH}$ to yield $o$-benzoquinone that is reminiscent of the Waddington mechanism for $\beta$-hydroxyperoxyl radicals. These results suggest $O$-hydroxyphenyl $+\mathrm{O}_{2}$ and decarbonylation of $\mathrm{O}$-benzoquinone serve as plausible $\mathrm{OH}$ and $\mathrm{CO}$ sources in combustion.
\end{abstract}

\section{Introduction}

Phenolic compounds, including alkylphenols, represent a substantial portion of lignin-derived biofuel stocks ${ }^{1}$ and the lighter fractions from lignite pyrolysis. ${ }^{2}$ They are also used as additives to enhance the oxidative stability of biodiesel and diesel. ${ }^{3-6}$

\footnotetext{
${ }^{a}$ School of Chemistry, University of Wollongong, Wollongong, NSW 2522, Australia. E-mail: adamt@uow.edu.au

${ }^{b}$ Lawrence Berkeley National Laboratory, Berkeley, CA 94720, USA

${ }^{c}$ Combustion Research Facility, Sandia National Laboratories, Livermore, CA 94551-0969, USA

${ }^{d}$ School of Chemistry, Physics and Mechanical Engineering, Faculty of Science and Engineering, Queensland University of Technology, Brisbane, QLD 4001, Australia ${ }^{e}$ Central Analytical Research Facility, Queensland University of Technology, Brisbane, QLD 4001, Australia

${ }^{f}$ Department of Chemical and Biomolecular Engineering, The University of Melbourne, Melbourne, VIC 3010, Australia

$\dagger$ Electronic supplementary information (ESI) available. See DOI: 10.1039/ c5cp02953h
}

Phenol is a product of catechol thermal decomposition, ${ }^{7}$ benzene and hydroxyl radical reactions ${ }^{8}$ as well as phenyl ${ }^{9}$ and benzyl radical oxidation. ${ }^{10}$

The pyrolysis of phenol proceeds with $\mathrm{H}$-migration and $\mathrm{CO}$ elimination to produce cyclopentadiene or, at higher temperatures, H-loss to produce the phenoxyl radical. ${ }^{11}$ Investigations into the phenol $+\mathrm{OH}$ reaction report the $\mathrm{H}$-abstraction product as the phenoxyl radical. ${ }^{12,13}$ However, at $>390 \mathrm{~K}, \mathrm{H}$-abstraction from the phenyl ring and $\mathrm{OH}$ addition reactions are also expected with the former process resulting in hydroxyphenyl radicals. ${ }^{14}$ The $o$-hydroxyphenyl radical is an intermediate in the pyrolysis for the $\beta$-04 aryl ether unit within G-type lignin). ${ }^{15}$ The addition of $\mathrm{O}_{2}$ to the $o$-hydroxyphenyl radical site will produce the $o$-hydroxyphenylperoxyl radical, with its hydroxy $\mathrm{H}$-atom within close proximity to the peroxyl radical substituent. As is the case for the $o$-methylphenylperoxyl radical, ${ }^{16,17} o$-hydroxyphenylperoxyl is expected to isomerise and eliminate $\mathrm{OH}$ via a phenoxyl $\mathrm{QOOH}$ reaction reported for dimethoxybenzene (a model compound 
intermediate to produce $o$-benzoquinone ( $o$-BQ), a known precursor to cyclopentadienone (CPO) $+\mathrm{CO} .{ }^{18-21}$ This mechanism was reported for the oxidation of protonated tyrosinyl radicals ${ }^{22}$ and has some similarities to the Waddington mechanism for $\beta$-hydroxyperoxyl radicals. ${ }^{23-25}$ Yet, to date, no direct experimental results have validated this mechanism for the $o$-hydroxyphenyl + $\mathrm{O}_{2}$ reaction system.

In this work, we report reactions of gas-phase $o$-hydroxyphenyl with $\mathrm{O}_{2}$ using two approaches: synchrotron-based time-resolved photoionisation mass spectrometry and distonic-ion mass spectrometry. The synchrotron-based method couples a slowflow kinetic reactor to a time-of-flight mass spectrometer and VUV photoionisation that allows detection of reaction products with kinetic and isomeric details. The distonic ion approach exploits charge-tagged derivatives of neutral radical species to study radical kinetics by ion-trap mass spectrometry. ${ }^{26}$ These distonic ion oxidation experiments build on a framework provided by previous studies of distonic phenyl ${ }^{27}$ and $o$-methylphenyl radical oxidation. ${ }^{17}$ In combination, we show that $\mathrm{OH}$ elimination follows the reaction of $o$-hydroxyphenyl radicals with $\mathrm{O}_{2}$ to form $o$-BQ. The stability of this nascent $o$-BQ is also investigated.

\section{Experimental}

\subsection{Synchrotron photoionisation mass spectrometry}

The $o$-hydroxyphenyl $+\mathrm{O}_{2}$ reaction was investigated using timeresolved photoionisation mass spectrometry ${ }^{28}$ at the Chemical Dynamics Beamline $^{29,30}$ at the Advanced Light Source (ALS at Lawrence Berkeley National Laboratories, USA). The apparatus comprises a slow-flow tube reactor, quasi-continuous vacuumultraviolet (VUV) synchrotron light source and an orthogonal acceleration time-of-flight mass spectrometer. $o$-Hydroxyphenyl radicals were generated within the flow tube by photolysis of $o$-bromophenol using a pulsed $\mathrm{KrF}$ excimer laser (248 $\mathrm{nm}$ ) operating at $4 \mathrm{~Hz}$ with a fluence of $c a .50 \mathrm{~mJ} \mathrm{~cm}^{-2}$.

The heatable quartz reactor flow tube is $62 \mathrm{~cm}$ long with a $1.05 \mathrm{~cm}$ inner diameter maintained at 4 Torr (533.3 Pa). Gas continuously escapes the reactor into a differentially pumped vacuum chamber through a $650 \mu \mathrm{m}$ pinhole situated $37 \mathrm{~cm}$ along the flow tube. In the experiments reported here, $o$-bromophenol, $\mathrm{O}_{2}$ gas, and $\mathrm{He}$ gas are supplied to the reactor through separate mass-flow controllers at the overall rate of $202 \mathrm{sccm}$. The $o$-bromophenol was entrained in He gas using a fritted bubbler with the liquid sample maintained at $291 \mathrm{~K}\left(18^{\circ} \mathrm{C}\right)$ and $\sim 573$ Torr $(76.4 \mathrm{kPa})$. The vapour pressure of $o$-bromophenol is roughly approximated at $291 \mathrm{~K}$ to be 0.17 Torr using Antoine parameters known for phenol. ${ }^{31}$ At $373 \mathrm{~K}$ and 4 Torr, number densities within the reactor are $c a .1 .7 \times 10^{12}$ molecule $\mathrm{cm}^{-3}$ for $o$-bromophenol, $7.7 \times 10^{15}$ molecule $\mathrm{cm}^{-3}$ for $\mathrm{O}_{2}$ gas, and a total of $9.6 \times$ $10^{16}$ molecule $\mathrm{cm}^{-3}$ for He gas. Reactions were conducted with the reactor temperature maintained at $373 \mathrm{~K}, 500 \mathrm{~K}$ and $600 \mathrm{~K}$. The temperature profile of the reactor is such that the length ca. $20 \mathrm{~cm}$ above the pinhole is maintained at the set temperature. Gas flow velocities are as follows: $10.1 \mathrm{~m} \mathrm{~s}^{-1}$ at $373 \mathrm{~K}$, $13.5 \mathrm{~m} \mathrm{~s}^{-1}$ at $500 \mathrm{~K}$, and $16.2 \mathrm{~m} \mathrm{~s}^{-1}$ at $600 \mathrm{~K}$. Total gas flow densities were: $1.0 \times 10^{17}$ molecule $\mathrm{cm}^{-3}$ at $373 \mathrm{~K}, 7.7 \times$ $10^{16}$ molecule $\mathrm{cm}^{-3}$ at $500 \mathrm{~K}$, and $6.4 \times 10^{16}$ molecule $\mathrm{cm}^{-3}$ at $600 \mathrm{~K}$.

The gas that escapes through the $650 \mu \mathrm{m}$ pinhole is sampled by a skimmer to create a near-effusive molecular beam that is intersected by quasi-continuous vacuum-ultraviolet (VUV) synchrotron light. Ions produced by photoionisation are detected using a $50 \mathrm{kHz}$ pulsed orthogonal-acceleration time-of-flight mass spectrometer. The photoionisation energy was typically scanned from 9 to $10 \mathrm{eV}$ with $0.025 \mathrm{eV}$ steps. Mass spectra are compiled into three-dimensional arrays of mass-to-change $(\mathrm{m} / \mathrm{z})$, reaction time, and photoionisation energy. All data are normalised for variations in the ALS photocurrent using a NIST-calibrated photodiode (SXUV-100, International Radiation Detectors Inc.). Background subtraction is achieved by subtracting the average signal during the $20 \mathrm{~ms}$ prior to the photolysis pulse from the dataset. The resulting photoionisation spectra and kinetic traces are normalised by the area under the curve and averaged together for each temperature. The error bars provided at a given photoionisation energy represent two standard deviations $(2 \sigma)$ for a mean of at least three measurements at 373 and $500 \mathrm{~K}$, and two measurements at $600 \mathrm{~K}$.

\subsection{Ion-trap mass spectrometry}

Distonic radical cation experiments were conducted on a modified Thermo Fisher Scientific LTQ ion-trap mass spectrometer (Thermo Fisher Scientific Inc., San Jose, USA) situated at the University of Wollongong. Radical precursor ions were generated by infusing methanolic solutions of $10 \mu \mathrm{M}$ 2-bromo-4-aminophenol $\left([\mathrm{M}+\mathrm{H}]^{+}\right.$ at $m / z 188$ and 190), 3-bromo-4-methylaniline $\left([\mathrm{M}+\mathrm{H}]^{+}\right.$at $m / z 186$ and 188), or 3-iodo-4-hydroxy- $N, N, N$-trimethylbenzenaminium iodide $\left([\mathrm{M}-\mathrm{I}]^{+}\right.$at $\left.\mathrm{m} / \mathrm{z} 278\right)$ into the electrospray ion source at

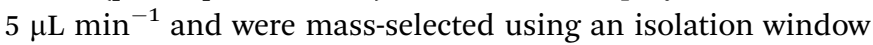
of 5-6 Th (mass-to-charge) for brominated, and 1-2 Th for the iodinated cations with a $q$-parameter of 0.250 . Mass spectra acquired with the ion-trap mass spectrometer and presented herein are an average of 50 scans unless otherwise stated. Typical instrumental settings: electrospray voltage (4-5 kV), capillary temperature $\left(250{ }^{\circ} \mathrm{C}\right)$, and sheath gas flow at 10-15, auxiliary gas flow at $0-5$ and sweep gas flow at 0 (arbitrary units). The normalised collision energy was typically $20-30 \%$ (ref. 32) for CID experiments with an activation time of $30 \mathrm{~ms}$ as defined within the control software.

2.2.1 Photodissociation (PD). Modifications to the ion-trap mass spectrometer required for PD of trapped ions are similar to those previously reported ${ }^{33,34}$ and are detailed elsewhere. ${ }^{35,36}$ At the beginning of a specified $\mathrm{MS}^{n}$ ion activation step, where laser PD is desired, the mass spectrometer transmits a signal to a digital delay generator that subsequently triggers the flashlamp of the Nd:YAG laser (4th harmonic, $\lambda=266 \mathrm{~nm}$ ) such that only a single laser pulse is delivered per MS $^{n}$ cycle. The unfocussed laser pulse ( $c a .30 \mathrm{~mJ} \mathrm{~cm}^{-2}$ ) is directed through a $2 \mathrm{~mm}$ orifice in the back lens of the ion-trap assembly to overlap with the ion cloud within the ion trap.

2.2.2 Ion-molecule reactions. Distonic radical cations generated within the ion trap were mass selected and then allowed to 
react with $\mathrm{O}_{2}$ for $0.030-10000 \mathrm{~ms}$ (set by the control software). Background $\mathrm{O}_{2}$ resides in the trap due to air entrained by the atmospheric pressure ESI source. Reactions were also conducted with an increased $\mathrm{O}_{2}$ concentration by using a $\mathrm{He}$ bath gas doped with $\mathrm{O}_{2}$ (770 \pm 45 ppm; BOC, Australia). Similarly, a He bath gas doped with oxygen-18 was used for isotopic labelling experiments.

The $\mathrm{O}_{2}$ concentration (molecule $\mathrm{cm}^{-3}$ ) within the ion-trap region was determined using the measured pseudo-first order rate coefficient for 3-carboxylatoadamantyl $+\mathrm{O}_{2}$ and its known secondorder rate coefficient of $8.5 \pm 0.4 \times 10^{-11} \mathrm{~cm}^{3}$ molecule ${ }^{-1} \mathrm{~s}^{-1}$ with the $\mathrm{O}_{2}$ concentration determined for each experiment. ${ }^{37}$ The background $\mathrm{O}_{2}$ concentration within the ion trap is typically $6.4 \times 10^{9}$ molecule $\mathrm{cm}^{-3}$ and the increased $\mathrm{O}_{2}$ concentrations ranged from 1.6-2.2 $\times 10^{11}$ molecule $\mathrm{cm}^{-3}$ with an $\mathrm{O}_{2}$-doped bath gas. The effective temperature of ions stored within a linear quadrupole ion trap has been estimated at $318 \pm 23 \mathrm{~K},{ }^{38}$ consistent with an earlier estimate of $307 \mathrm{~K}^{37}$

The kinetic plots that show ion signal decay with increasing reaction time were produced by integrating the ion signal intensity over a selected mass-to-charge range and normalising it to the integrated total ion signal intensity. The normalised integrated ion signal intensity is then averaged for at least 10 scans and plotted against reaction time $(0.030-10000 \mathrm{~ms})$ to track changes in ion signal intensity due to reactions with $\mathrm{O}_{2}$. Measured pseudo-first order rate coefficients $\left(k_{1 \mathrm{st}}\right)$ were obtained by fitting eqn (1) to the average normalised integrated peak intensity against reaction time, for a select mass-to-charge range, using the Levenberg-Marquardt algorithm. Satisfactory fits with eqn (1) are consistent with pseudo-first order kinetic behaviour. Thus, allowing the second-order rate coefficient $\left(k_{2 n d}\right)$ to be calculated using eqn (2) with a measured $\left[\mathrm{O}_{2}\right]$. The residual plots accompanying kinetic curves in Fig. 5, Fig. S7, and S8 (ESI $\dagger$ ) show the difference between the average normalised integrated ion signal intensity and the expected value from eqn (1), i.e. the residuals, plotted as a function of reaction time.

$$
\begin{gathered}
y=A_{0} \exp \left(-k_{1 \mathrm{st}} t\right)+\text { constant } \\
k_{2 \mathrm{nd}}=\frac{k_{1 \mathrm{st}}}{\left[\mathrm{O}_{2}\right]}
\end{gathered}
$$

At least five kinetic decay curves were acquired in succession to ensure consistent conditions, with one decay curve taking 20-30 min to acquire. For the ion-molecule reactions below, pseudo-first order kinetic character was observed. The second order rate coefficient for 5-ammonium-2-hydroxyphenyl $+\mathrm{O}_{2}$ is an average from 17 decay curves over three experiments at low $\left[\mathrm{O}_{2}\right]$ and 20 decay curves over two experiments at increased $\left[\mathrm{O}_{2}\right]$. The 5-ammonium-2-methylphenyl $+\mathrm{O}_{2}$ second order rate coefficient is calculated as the average of 19 decay curves at low $\left[\mathrm{O}_{2}\right]$ and 30 decay curves at increased $\left[\mathrm{O}_{2}\right]$ over three experiments at each concentration. The second-order rate coefficient for $5-(\mathrm{N}, \mathrm{N}, \mathrm{N}-$ trimethylammonium)-2-hydroxyphenyl radical $+\mathrm{O}_{2}$ is an average of 5 decay curves at low $\left[\mathrm{O}_{2}\right]$. Reported reaction efficiencies were calculated from the second-order rate coefficients as a percentage of the reactants' collision frequency estimated using the Langevin collision model for ion-molecule collision pairs. ${ }^{39}$
Statistical uncertainty from fitting pseudo-first order rate coefficients $\left(k_{1 \mathrm{st}}\right)$ to experimental decay curves was typically $2 \sigma \leq 10 \%$. Systematic uncertainty in the ion-trap pressure and $\mathrm{O}_{2}$ concentration, including the generation of neutrals and charged species with mass-to-charge less than the low mass cut-off (50 Th) result in an upper limit of $50 \%$ uncertainty in the $\mathrm{O}_{2}$ concentration that is accumulated in reported second-order rate coefficients and reaction efficiencies.

\subsection{Quantum chemical calculations}

Reaction enthalpies were calculated from electronic energies computed with the G3X-K composite method $^{40}$ in Gaussian 09. ${ }^{41}$ G3X-K is a modified G3SX composite method that uses M06-2X density functional theory in place of B3LYP and is parameterised for thermochemical kinetics. It is capable of reproducing barrier heights in the DBH24/08 test set ${ }^{42}$ to within $1 \mathrm{kcal} \mathrm{mol}^{-1}$, on average. ${ }^{40}$ The CBS-QB3 method was used for the calculation of adiabatic ionisation energies (AIE) and cation dissociation barriers, with an estimated error of $1 \mathrm{kcal} \mathrm{mol}^{-1}(0.05 \mathrm{eV})$ for $\mathrm{AIEs}^{43,44}$ and $2 \mathrm{kcal} \mathrm{mol}^{-1}$ for barriers from the DBH24/08 database. ${ }^{42}$ All stationary points were characterised as either minima (no imaginary frequencies) or transition states (one imaginary frequency whose normal mode projection approximates motion along a reaction coordinate). The assignment of a transition state between minima was verified by IRC calculations. The M06-2X geometries and frequencies and G3X-K energies were used to calculate preliminary product ratios within the MultiWell 2013 suite of programs. ${ }^{45}$ All reported energies include the zeropoint energy correction for $0 \mathrm{~K}$ enthalpies and AIEs.

\subsection{Materials}

3-Bromo-4-methylaniline, 4-amino-2-bromophenol, oxygen-18 (97\%), and $o$-bromophenol (98\%) were purchased from Sigma Aldrich. Gases and reagents obtained from commercial sources were used without further purification. The synthesis of 3-iodo4-hydroxy- $N, N, N$-trimethylbenzenaminium iodide is described in Section 1 of the ESI. $\dagger$

\section{Results and discussion}

\subsection{Synchrotron photoionisation mass spectrometry: $o$-hydroxyphenyl $+\mathrm{O}_{2}$}

Fig. $1 \mathrm{a}$ is a product mass spectrum after photolysis of $o$-bromophenol with no $\mathrm{O}_{2}$ added to the reactor, serving as a background measurement. The spectrum is integrated from 0 to $20 \mathrm{~ms}$ after photolysis at a photoionisation energy of $10 \mathrm{eV}$ with a reactor temperature of $373 \mathrm{~K}$. Major photolysis product peaks are present at $m / z 92$ and 94. The photoionisation (PI) spectra for $m / z 92$ and 94 (not shown) are well matched to the integrated photoelectron spectrum for cyclopenta-2,4-dien-1-ylidenemethanone $\left(\mathrm{C}_{5} \mathrm{H}_{4} \mathrm{CO} \text {, AIE }=8.09 \mathrm{eV}\right)^{46-48}$ and the known photoionisation spectrum for phenol $\left(\mathrm{C}_{6} \mathrm{H}_{5} \mathrm{OH}\right.$, AIE $\left.=8.49 \mathrm{eV}\right),{ }^{49-51}$ respectively. However, since the characteristic AIEs are below the photoionisation energy range scanned, these are tentative assignments for these background species. As an aside, 

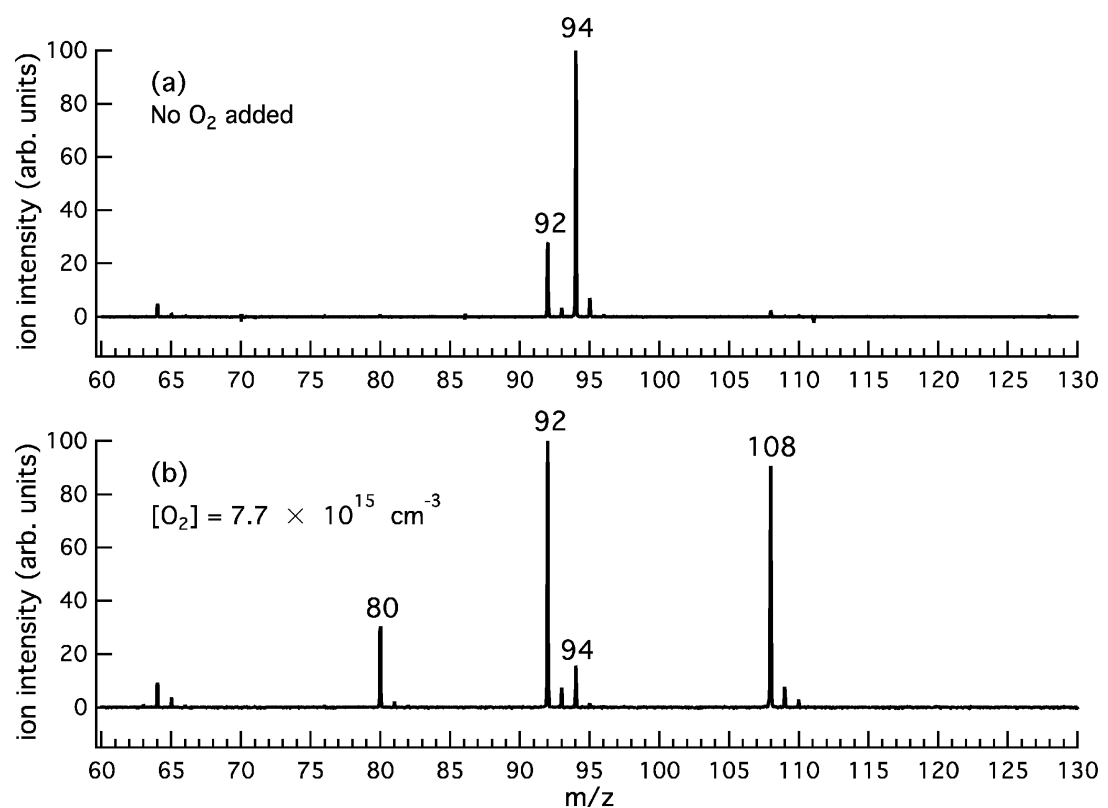

Fig. 1 Product photoionisation mass spectra at $373 \mathrm{~K}$ and $10 \mathrm{eV}$ integrated $0-20 \mathrm{~ms}$ after $248 \mathrm{~nm}$ photolysis of (a) o-bromophenol and (b) o-bromophenol in the presence of additional $\mathrm{O}_{2}\left(7.7 \times 10^{15}\right.$ molecule $\left.\mathrm{cm}^{-3}\right)$. In product spectrum (b) $\mathrm{m} / \mathrm{z} 108$ and 80 are reaction product peaks but, as discussed in the text, a portion of the $\mathrm{m} / \mathrm{z} 80$ signal may arise from dissociative ionisation of $0-B Q$ (assigned to $\mathrm{m} / \mathrm{z} 108$ ).

cyclopenta-2,4-dien-1-ylidenemethanone $\left(\mathrm{C}_{5} \mathrm{H}_{4} \mathrm{CO}, \mathrm{m} / \mathrm{z}\right.$ 92) may arise from $o$-bromophenol photolysis via $\mathrm{HBr}$ loss $^{52}$ and phenol $\left(\mathrm{C}_{6} \mathrm{H}_{5} \mathrm{OH}, \mathrm{m} / z\right.$ 94) is probably formed via $\mathrm{H}$-abstraction by the $\mathrm{m} / \mathrm{z} 93$ radical from the abundant $o$-bromophenol precursor.

Fig. $1 \mathrm{~b}$ is a product mass spectrum from photolysis of $o$-bromophenol in the presence of $7.7 \times 10^{15}$ molecule $\mathrm{cm}^{-3} \mathrm{O}_{2}$. The new product peaks at $\mathrm{m} / \mathrm{z} 80,108$ and the minor peak at $\mathrm{m} / z \mathrm{z} 110$ are consistent with $\mathrm{C}_{5} \mathrm{H}_{4} \mathrm{O}, \mathrm{C}_{6} \mathrm{H}_{4} \mathrm{O}_{2}$, and $\mathrm{C}_{6} \mathrm{H}_{6} \mathrm{O}_{2}$ and are attributed to the $o$-hydroxyphenyl $+\mathrm{O}_{2}$ reaction. The PI spectra for $\mathrm{m} / \mathrm{z} 80$ and 108, integrated 0 to $20 \mathrm{~ms}$ after photolysis at $373 \mathrm{~K}$, are provided in Fig. $2 \mathrm{a}$ and b. PI spectra at $500 \mathrm{~K}$ and $600 \mathrm{~K}$ are provided in the ESI $\dagger$ (Fig. S1 and S2, respectively). The PI onsets for $m / z 80$ at $9.4 \mathrm{eV}$ and $m / z 108$ at $9.2 \mathrm{eV}$ are in agreement with reference spectra for cyclopentadienone (CPO, $\mathrm{m} / \mathrm{z} 80$ ) and $o$-benzoquinone ( $o$-BQ, $\mathrm{m} / \mathrm{z} 108),{ }^{53-55}$ and consistent with AIEs provided in Table 1. Ionization onsets for $\mathrm{CPO}$ and $o$-BQ were recently reported by Ormond et al..$^{53}$ and compared within the inset of Fig. 2. The $p$-benzoquinone isomer can be excluded as a $m / z 108$ product contributor as its AIE is $9.96 \mathrm{eV}$ with a sharp photoionisation onset, ${ }^{55,56}$ and there is no such feature in the PI spectrum up to $10 \mathrm{eV}$. The $\mathrm{m} / \mathrm{z} 109$ signal present in mass spectra obtained at 373, 500 and $600 \mathrm{~K}$ (ESI, $\dagger$ Fig. S3) could result, in part, from decomposition of $o$-hydroxyphenylperoxyl to $o$-hydroxyphenoxyl $+\mathrm{O}\left({ }^{3} \mathrm{P}\right)$. The hydroxyphenoxyl cation is expected at $m / z 109$, however unequivocal assignment of the $\mathrm{m} / z 109$ species is confounded by the ${ }^{13} \mathrm{C}$ isotope peak of the dominant $\mathrm{m} / \mathrm{z} 108$ product. In unpublished studies, we have observed phenoxyl radical decay that is kinetically matched to the growth of a +1 Da ion signal intensity. A $m / z 110$ product ion is present in Fig. S3 (ESI $\dagger$ ) and kinetic traces in Fig. S5 (ESI $\dagger$ ) show that the appearance of $\mathrm{m} / \mathrm{z} 110$ ions is delayed relative to $\mathrm{m} / \mathrm{z} 108$ ions (a primary product kinetic reference). Therefore,

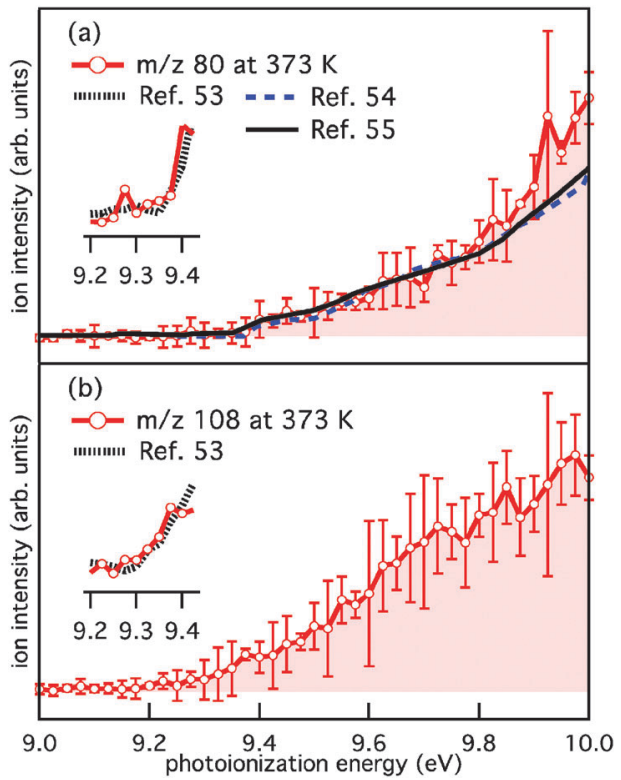

Fig. 2 Photoionisation spectra integrated $0-20 \mathrm{~ms}$ after photolysis for (a) $\mathrm{m} / \mathrm{z} 80$ and (b) $\mathrm{m} / \mathrm{z} 108$ from o-hydroxyphenyl $+\mathrm{O}_{2}$ at $373 \mathrm{~K}$. Each spectrum is an average of three PI spectra and the $2 \sigma$ statistical uncertainty is represented by vertical error bars. Figures inset within (a) and (b) compare the experimental PI spectra near the onset to reference spectra for $\mathrm{CPO}$ and o-BQ from ref. 53 (1000 K). Reference PI spectra are also provided in (a) for CPO from ref. 54 and 55 (873 K).

the delayed appearance of $\mathrm{m} / \mathrm{z} 110$ ions could be explained via $\mathrm{H}$-abstraction by the $o$-hydroxyphenoxyl radical to produce $o$-catechol $\left(\mathrm{C}_{6} \mathrm{H}_{4} \mathrm{OHOH}, \mathrm{m} / z\right.$ 110).

The detection of $o-\mathrm{BQ}(\mathrm{m} / \mathrm{z} 108)$ is rationalised by $\mathrm{O}_{2}$ addition to the $o$-hydroxyphenyl radical, followed by isomerisation 
Table 1 Measured photoionisation thresholds for $\mathrm{m} / \mathrm{z} 80$ and $108 \mathrm{com}$ pared to calculated CBS-QB3 AIE for CPO, O-BQ and $p$-benzoquinone. Literature vertical (VIE) and adiabatic ionisation energies (AIE) are provided with the original reference

\begin{tabular}{llll}
\hline & \multicolumn{3}{l}{ Measured Calculated } \\
Species & $(\mathrm{eV})$ & AIE $(\mathrm{eV})$ & Literature values \\
\hline $\begin{array}{l}\text { Cyclopentadienone } \\
\begin{array}{l}\text { CPO } m / z \text { 80) } \\
o \text {-Benzoquinone }\end{array}\end{array}$ & 9.4 & 9.41 & $9.41 \pm 0.01(\mathrm{AIE})^{53}$ \\
$\begin{array}{l}(o-\mathrm{BQ}, m / z \text { 108) } \\
o \text {-Hydroxyphenoxyl radical } \\
(m / z \text { 109) }\end{array}$ & 9.2 & 9.18 & $9.3 \pm 0.1(\mathrm{AIE})^{53}$ \\
$\begin{array}{l}o \text {-Hydroxyphenol } \\
(\text { catechol, } m / z \text { 110) } \\
p \text {-Benzoquinone }(p \text {-BQ })\end{array}$ & 8.14 & \\
\hline
\end{tabular}

of the hydroxyphenylperoxyl intermediate to hydroperoxyphenoxyl and subsequent $\mathrm{OH}$ loss to form $o$-BQ (Scheme 1). This pathway is analogous to the $\mathrm{O}_{2}$ addition and subsequent $\mathrm{OH}$ loss mechanism that operates in the $o$-methylphenyl $+\mathrm{O}_{2}$ reaction ${ }^{16,17}$ and $\mathrm{OH}$ loss in the Waddington mechanism for $\beta$-hydroxyperoxyl radicals. ${ }^{23,24}$ Scheme 1 also includes pathways from $o$-BQ that lead to CPO and the CPO radical cation that will now be discussed.

Included in Fig. 2a are reference PI spectra for CPO from Yang et $a l .{ }^{54}$ and Parker et al. ${ }^{55}$ The close agreement between the $m / z 80$ and reference PI spectra shown in Fig. 2a from 9 to $9.8 \mathrm{eV}$ support our assignments of $\mathrm{m} / \mathrm{z} 80$ as CPO. It is evident that at PI energies $\geq 9.8 \mathrm{eV}$ all $\mathrm{m} / z$ 80 PI spectra diverge with the reference spectra under-predicting the current experimental data. Additional PI spectra acquired at 500 and $600 \mathrm{~K}$ (Fig. S1 and S2, ESI $\dagger$ ) also diverge from the reference spectra at PI energies $\geq 9.8 \mathrm{eV}$.
The possibility of other $\mathrm{C}_{5} \mathrm{H}_{4} \mathrm{O}$ isomers contributing to the $\mathrm{m} / \mathrm{z} 80$ ion signal was ruled out by calculating AIEs for closedshell linear $\mathrm{C}_{5} \mathrm{H}_{4} \mathrm{O}$ isomers listed in Table $\mathrm{S} 1$ (ESI $\dagger$ ). Isomers were excluded on the basis of having: an AIE $<9.2 \mathrm{eV}$, or an AIE $>10.0 \mathrm{eV}$ and a relatively high formation enthalpy. As it stands, CPO is the only plausible isomer contributing to the $\mathrm{m} / z 80$ PI spectra, however, the source of neutral CPO and the cause of the disparity around $9.8 \mathrm{eV}$ in the $\mathrm{m} / \mathrm{z} 80 \mathrm{PI}$ spectra (Fig. 2a) require further examination.

The systematic differences between the $\mathrm{m} / \mathrm{z} 80$ signal and CPO reference spectra in Fig. 2a at photoionisation energies $\geq 9.8 \mathrm{eV}$ could arise from dissociative ionisation of higher mass species, where $o$-BQ is a likely candidate. It is known that dissociative ionisation of 1,2-naphthoquinone and 9,10-phenanthrenequinone result in CO loss (both contain the $o$-BQ substructure).$^{58}$ Fig. S3 (ESI $\dagger$ ) shows product mass spectra at 373 , 500 and $600 \mathrm{~K}$ integrated over two energy ranges; 9.40-9.75 eV (Fig. S3a-c, ESI $\dagger$ ) and 9.85-10.00 eV (Fig. S3d-f, ESI $\dagger$ ). These mass spectra reveal some variation in the product ratios but no additional product signals. Comparing the kinetic traces for $\mathrm{m} / \mathrm{z} 80$ and 108 at $500 \mathrm{~K}$ integrated over 9.40-9.75 eV (Fig. S4a, $\mathrm{ESI} \dagger)$ shows that the kinetic traces are clearly different and consistent with the dominant fraction of each ion population arising from photoionisation of different neutrals. However, at higher energies (9.85-10.00 eV, Fig. S4b, ESI $\dagger$ ), the $m / z 80$ and 108 kinetic traces appear more similar - this is consistent with a portion of $\mathrm{C}_{6} \mathrm{H}_{4} \mathrm{O}_{2}(108 \mathrm{Da})$ undergoing dissociative ionisation to yield product ions with $\mathrm{m} / \mathrm{z}$ 80. Furthermore, the potential energy scheme for CO loss from the $o$-BQ radical cation $(\mathrm{m} / \mathrm{z} 108)$ provided in Fig. 3 shows the cation dissociation barrier to be $9.7 \mathrm{eV}$ relative to neutral $o$-BQ. These results

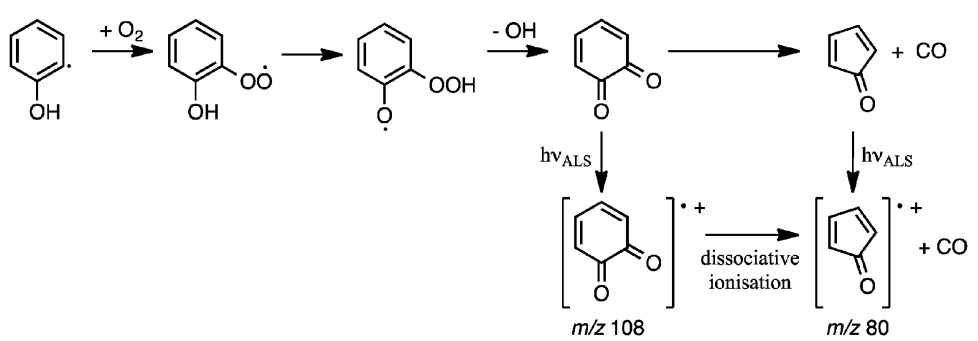

Scheme 1

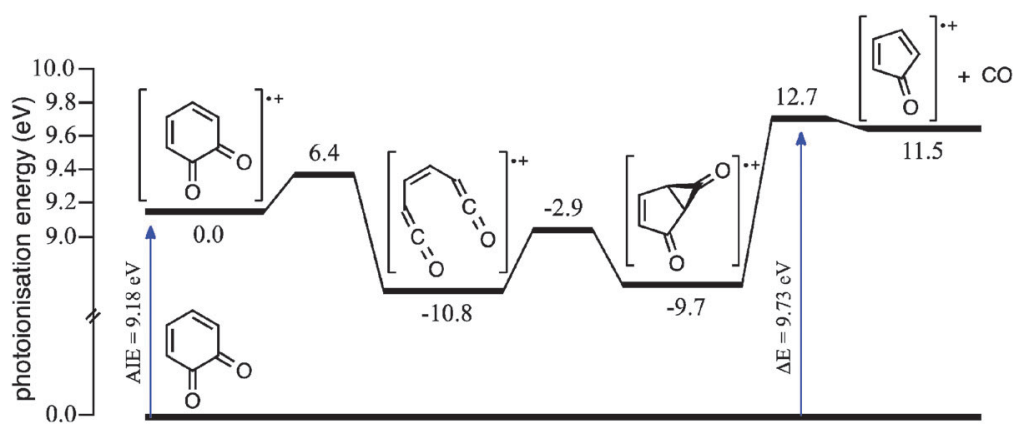

Fig. 3 Potential energy schematic that depicts loss of $C O$ from the $\mathrm{O}-\mathrm{BQ}$ radical cation. $\mathrm{CBS}-\mathrm{QB} 30 \mathrm{~K}$ enthalpies are provided in $\mathrm{kcal}^{\mathrm{mol}}{ }^{-1}$ relative to the $\mathrm{O}-\mathrm{BQ}$ radical cation. $\mathrm{CBS}-\mathrm{QB} 3 \mathrm{AIE}$ and dissociation barrier are provided in eV relative to $\mathrm{O}-\mathrm{BQ}$. 
support the proposition that at photoionisation energies $\geq 9.8 \mathrm{eV}$ some of the $\mathrm{m} / \mathrm{z} 80$ signal arises from the dissociative ionisation of $o$-BQ. This contribution is in addition to the ionisation of CPO produced within the reactive flow.

Analogous to product pathways of the phenylperoxyl radical in phenyl $+\mathrm{O}_{2}$ reactions, ${ }^{59-62} \mathrm{CPO}$ could be produced after decomposition of hydroxyl-substituted oxepinoxyl radicals. Unimolecular reaction pathways leading directly to CPO are discounted on the basis of experiments in Section 3.2 and prohibitively high energy pathways reported in Section 3.3.3. Ultimately, we propose that the $m / z 80$ and 108 products are generated according to processes summarised in Scheme 1: the $o$-hydroxyphenyl radical undergoes $\mathrm{O}_{2}$ addition to form the hydroxyphenylperoxyl radical and subsequent $\mathrm{OH}$ loss to produce $o$-BQ. And, a portion of the nascent vibrationally-excited $o$-BQ population then decomposes via decarbonylation to produce CPO. ${ }^{18-20}$ In addition, dissociative ionisation of $o$-BQ possibly contributes to the measured $\mathrm{m} / \mathrm{z} 80$ signal at energies $\geq 9.8 \mathrm{eV}$.

To further establish connections between the reaction products of $o$-hydroxyphenyl $+\mathrm{O}_{2}(c f$. Scheme 1), charge-tagged derivatives of $o$-hydroxyphenyl radicals were prepared within an ion-trap mass spectrometer (at the University of Wollongong). The study of distonic radical ions can provide useful insight into the reactions of their neutral radical counterparts. The presence of a relatively unreactive charged substituent enables isolation and manipulation of reactive intermediates using iontrap mass spectrometry, while products arise from reactions with the spatially separated radical moiety. ${ }^{17,63,64}$ Quantum chemical calculations were also conducted, and discussed later in Section 3.3, to rationalise experimental results for both the neutral and charge-tagged systems.

\subsection{Ion-trap mass spectrometry: distonic o-hydroxyphenyl $+\mathrm{O}_{2}$}

Photodissociation (PD, $\lambda=266 \mathrm{~nm}$ ) of isolated $\mathrm{m} / z 188$ and 190 ions $\left([\mathrm{M}+\mathrm{H}]^{+}\right.$, assigned 3-bromo-4-hydroxybenzaminium cation) resulted in the $m / z 109$ signal in Fig. 4a. The $m / z 109$ ion, consistent with $\mathrm{Br}$ loss, was assigned to the 5-ammonium-2hydroxyphenyl radical cation shown in Scheme 2. Isolation of this radical cation in the presence of background $\mathrm{O}_{2}(6.4 \times$ $10^{9}$ molecules $\mathrm{cm}^{-3}$ ) resulted in a major product ion at $\mathrm{m} / z 124$ and a minor product ion at $m / z 96(<1 \%)$ that both grew in with increasing reaction times (0.030-10000 ms). A mass spectrum acquired with $2000 \mathrm{~ms}$ reaction time is shown in Fig. 4b. The $\mathrm{m} / \mathrm{z} 124$ product ion is rationalised by $\mathrm{O}_{2}$ addition to the chargetagged 2-hydroxyphenyl radical followed by prompt $\mathrm{OH}$ elimination to yield 4-ammonium-2-benzoquinone.

The mass spectrum in Fig. 4c, from isolation and subsequent collision-induced dissociation (CID) of $\mathrm{m} / \mathrm{z} 124$ product ions, shows major signals at $m / z 96$ and 107 and minor signals at $m / z 79$ and 81 . The product ion at $m / z 96(-28 \mathrm{Da})$ is consistent with decarbonylation of ammonium-tagged $o$-BQ to yield ammonium-tagged CPO + CO. Fragment ions at $\mathrm{m} / \mathrm{z} 107,79$, and 81 are assigned to loss of $\mathrm{NH}_{3}(-17 \mathrm{Da}), \mathrm{NH}_{3}+\mathrm{CO}(-45 \mathrm{Da})$ and $\mathrm{NC}_{2} \mathrm{H}_{5}$ or $\mathrm{C}_{2} \mathrm{H}_{3} \mathrm{O}(-43 \mathrm{Da})$ from $\mathrm{m} / \mathrm{z} 124$, respectively. To verify these assignments, ${ }^{18} \mathrm{O}_{2}$ was introduced into the ion trap and reacted with $\mathrm{m} / z 109$ radical cations. The $\mathrm{m} / z 126$ ions
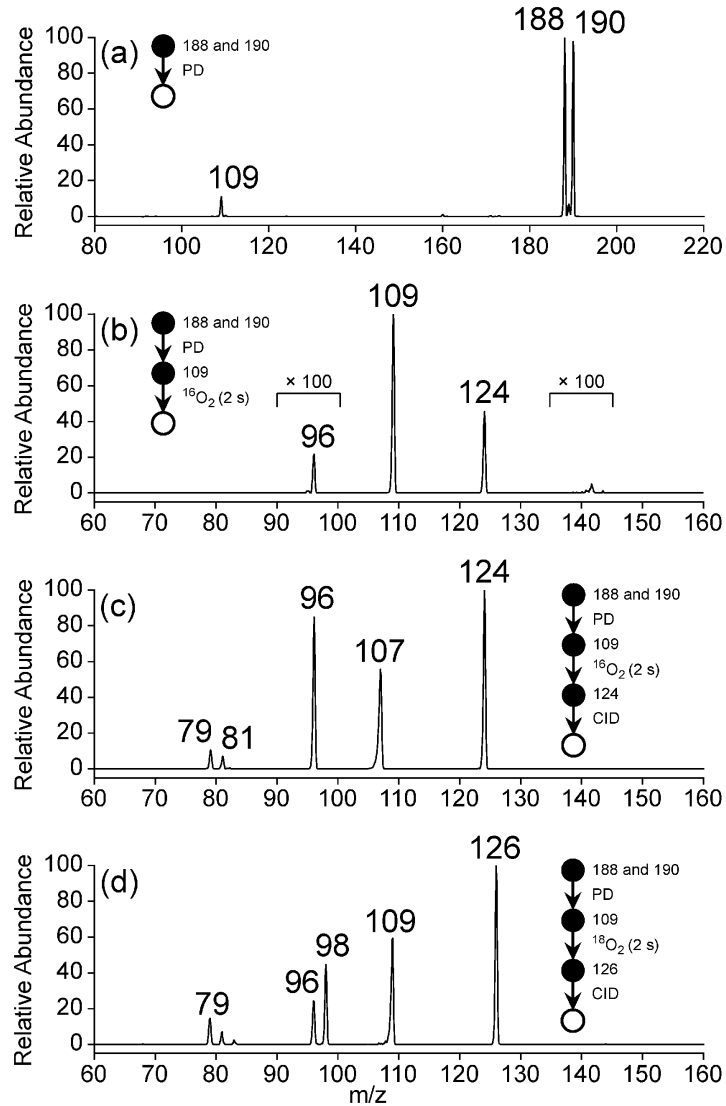

Fig. 4 Mass spectra resulting from (a) PD of 3-bromo-4-hydroxybenzenaminium ( $\mathrm{m} / \mathrm{z} 188$ and 190), (b) isolation of $\mathrm{m} / \mathrm{z} 109$ ions resulting from $266 \mathrm{~nm}$ PD of 3-bromo-4-hydroxybenzenaminium and storage for 2 seconds in the presence of background $\mathrm{O}_{2}\left(10^{9}\right.$ molecules $\left.\mathrm{cm}^{-3}\right)$, and (c) CID of the product ion at $\mathrm{m} / \mathrm{z} 124$. Experiments were repeated with ${ }^{18} \mathrm{O}_{2}$ and (d) the product ion at $m / z 126$ was subjected to CID.

produced are consistent with ${ }^{18} \mathrm{O}_{2}$ addition and ${ }^{18} \mathrm{OH}$ loss (-19 Da, Fig. 4d) and exclude any contribution of $\mathrm{NH}_{3}$ loss ( $\left.-17 \mathrm{Da}\right)$. Isolation and subsequent CID of the $\mathrm{m} / \mathrm{z} 126$ ions resulted in fragments at $m / z 96$ and 98 consistent with loss of $\mathrm{C}^{18} \mathrm{O}$ and $\mathrm{C}^{16} \mathrm{O}$ from ${ }^{18} \mathrm{O}$-labelled $o$-BQ to yield CPO. Taken together, these data demonstrate a connection between the $o$-BQ intermediate $(\mathrm{m} / \mathrm{z} 124)$ and the CPO structure $(\mathrm{m} / \mathrm{z} 96)$ via processes summarised in Scheme 2. These data do not provide evidence for a "phenyl-like" oxidation mechanism for the direct formation of CPO via phenoxyl and oxepinoxyl radicals. ${ }^{59-62}$ Other fragment ions at $\mathrm{m} / \mathrm{z} 79,81,83$, and 109 are assigned to loss of $\mathrm{NH}_{3}+\mathrm{C}^{18} \mathrm{O}(-47 \mathrm{Da}), \mathrm{NH}_{3}+\mathrm{C}^{16} \mathrm{O}$ or $\mathrm{C}_{2} \mathrm{H}_{3}{ }^{18} \mathrm{O}(-45 \mathrm{Da}), \mathrm{NC}_{2} \mathrm{H}_{5}$ or $\mathrm{C}_{2} \mathrm{H}_{3}{ }^{16} \mathrm{O}(-43 \mathrm{Da})$, and $\mathrm{NH}_{3}(-17 \mathrm{Da})$ from $\mathrm{m} / \mathrm{z} 126$, respectively.

Potential energy schemes for formation of $o$-BQ and CPO are compared and discussed for both neutral and distonic cases in Section 3.3. Reactions of the PD generated 5-ammonium-2hydroxyphenyl radical cation $(m / z \quad 109)$ with $\mathrm{O}_{2}$ were characterised further by kinetic measurements.

3.2.1 Distonic ion $+\mathrm{O}_{2}$ reaction kinetics. Product mass spectra for the reactions of $\mathrm{m} / \mathrm{z} 109$ ions with background $\mathrm{O}_{2}$ $\left(\left[\mathrm{O}_{2}\right]=6.4 \pm 0.4 \times 10^{9}\right.$ molecules $\left.\mathrm{cm}^{-3}\right)$ and increased $\mathrm{O}_{2}$ concentrations $\left(\left[\mathrm{O}_{2}\right]=1.6-2.2 \times 10^{11}\right.$ molecules $\left.\mathrm{cm}^{-3}\right)$ were 


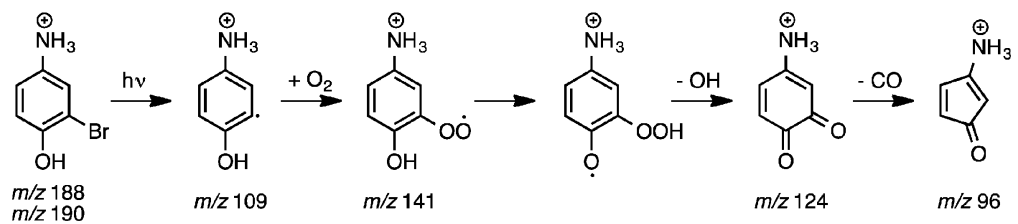

Scheme 2
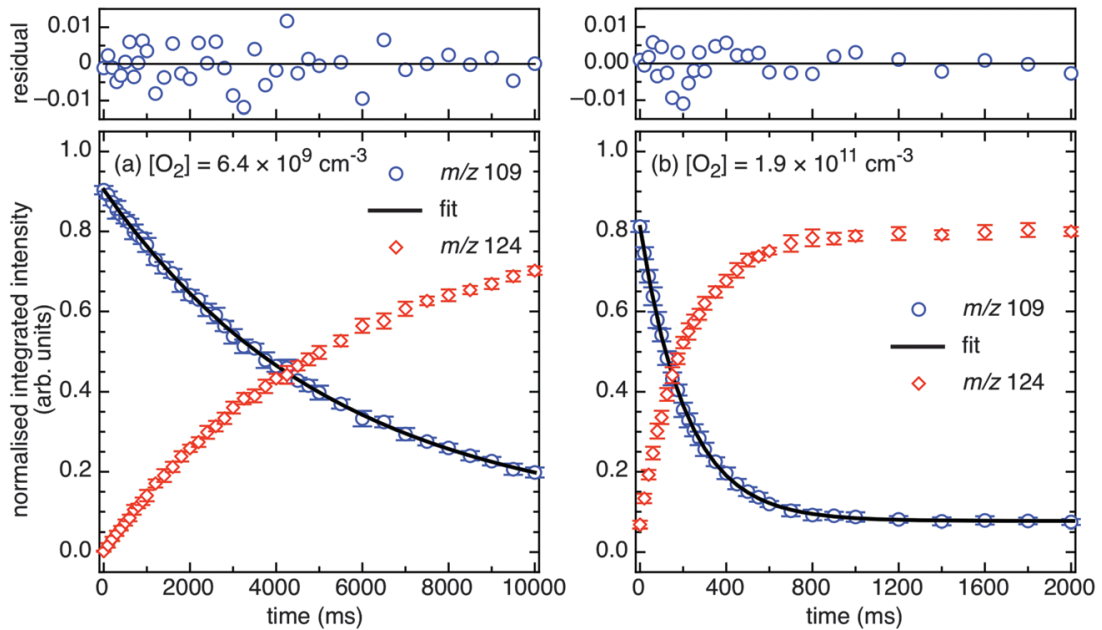

Fig. 5 Kinetic curves for $\mathrm{m} / \mathrm{z} 109$ (solid blue circles), from PD of 3-bromo-4-hydroxybenzaminium cations, in reactions with (a) background $\mathrm{O}_{2}$ $\left(6.4 \times 10^{9}\right.$ molecules $\left.\mathrm{cm}^{-3}\right)$ and $(\mathrm{b})$ increased $\mathrm{O}_{2}\left(1.9 \times 10^{11}\right.$ molecules $\left.\mathrm{cm}^{-3}\right)$. Residual plots from the fitting of eqn (1) are provided above. The $\mathrm{m} / \mathrm{z} 124$ product data are shown (red diamonds) and track with a rate coefficient in agreement with the $\mathrm{m} / \mathrm{z} 109$ decay (within $2 \sigma$ ). Error bars are $1 \sigma$.

recorded as a function of reaction time. The normalised integrated intensity for a selected mass-to-charge range (1-2 Th) was plotted against reaction time (0.030 to $10000 \mathrm{~ms})$ to produce kinetic curves that describe decay of $m / z 109$ ion signal intensity due to reactions with $\mathrm{O}_{2}$.

A single exponential decay (eqn (1)) was satisfactorily fitted to the experimental data, in accord with pseudo-first order kinetic behaviour. Representative kinetic curves for $m / z 109$ and 124 ions are provided in Fig. 5 with fitted data and residuals from eqn (1) for $m / z 109$ signal decay. The $k_{1 \text { st }}$ values for $m / z 109$ signal decay and $m / z 124$ signal growth are in agreement (e.g., in Fig. $5 \mathrm{a}, 1.9 \pm 0.2 \mathrm{~s}^{-1}$ compared to $1.8 \pm 0.1 \mathrm{~s}^{-1}$ within $\left.2 \sigma\right)$ and the $\mathrm{m} / \mathrm{z} 124$ intensity is well matched to the $\mathrm{m} / \mathrm{z} 109$ signal decay. This indicates that $\mathrm{m} / \mathrm{z} 124$ ions are the main reaction product from depletion of $m / z 109$ ions. As shown in Fig. 5b, at increased $\mathrm{O}_{2}$ concentrations the $\mathrm{m} / \mathrm{z} 109$ ion signal intensity ultimately approaches a constant value of $c a .10 \%$ at $1000 \mathrm{~ms}$ and remains constant up to a reaction time limit of $10000 \mathrm{~ms}$. This indicates the presence of an unreactive isomer (or isomers) and is accounted for by the constant offset included in eqn (1).

Additional experiments that compare the oxidation kinetics of the ammonium-tagged $o$-hydroxyphenyl and $o$-methylphenyl radical cations along with trimethylammonium-tagged analogues are now described. Sample kinetic plots are provided in Fig. S7 (ESI $\dagger$ ) for oxidation of 5-ammonium-2-methylphenyl radical cations $(\mathrm{m} / \mathrm{z} 107)$ and in Fig. S8 (ESI $\dagger)$ for 5-(N,N,N-trimethylammonium)-2-hydroxyphenyl radical cations $(\mathrm{m} / \mathrm{z} 151)$. For reactions of 5-ammonium-2-methylphenyl radical cations $(\mathrm{m} / \mathrm{z} 107)$ the non-zero horizontal offset (shown in Fig. S7b, ESI $\dagger$ ) is $c a .40 \%$ of the isolated $\mathrm{m} / \mathrm{z} 107$ ion population. Interestingly, $k_{1 \mathrm{st}}$ values for 5-ammonium-2-methylphenyl radical $(\mathrm{m} / \mathrm{z} 107)$ and 5-ammonium2-hydroxyphenyl radical $(\mathrm{m} / \mathrm{z}$ 109) signal decay are separable with $2 \sigma$ uncertainty, where the $k_{1 \text { st }}$ for the 5-ammonium-2hydroxyphenyl radical cations is reproducibly greater by $c a .15 \%$. In the case of trimethylammonium-tagged $o$-hydroxyphenyl radical $+\mathrm{O}_{2}$ reactions, the $\mathrm{m} / \mathrm{z} 151$ ion population can be completely depleted by $\mathrm{O}_{2}$ reaction, suggesting that a pure population of trimethylammonium-tagged $o$-hydroxyphenyl radicals are formed from PD of the precursor. This observation is consistent with our previous investigation of trimethylammonium-tagged $o$-methylphenyl $+\mathrm{O}_{2}$ reaction kinetics ${ }^{17}$ and may be attributed to the greater number of internal degrees of freedom from the trimethylammonium substituent thus reducing the propensity for isomerisation.

Second-order rate coefficients $\left(k_{2 n d}, \mathrm{~cm}^{3}\right.$ molecule $\left.{ }^{-1} \mathrm{~s}^{-1}\right)$ and reaction efficiencies $(\Phi \%)$ derived from fitted pseudo-first order rate coefficients $\left(k_{1 \mathrm{st}}\right)$ are reported in Table 2. Collision frequencies were calculated using the Langevin collision model. ${ }^{39}$ Kinetic measurements were conducted at background $\mathrm{O}_{2}\left(\left[\mathrm{O}_{2}\right]=\right.$ $6.4 \pm 0.4 \times 10^{9}$ molecule $\mathrm{cm}^{-3}$ ) and increased $\mathrm{O}_{2}$ concentrations $\left(\left[\mathrm{O}_{2}\right]=1.6-2.2 \times 10^{11}\right.$ molecule $\left.\mathrm{cm}^{-3}\right)$. Repeated kinetic measurements provided consistent results and statistical uncertainties from fitting $k_{1 \text { st }}$ were typically $2 \sigma \leq 10 \%$. These results indicate stable absolute $\mathrm{O}_{2}$ concentrations within the ion trap as indicated by the linear relationship between $k_{1 \mathrm{st}}$ and $\left[\mathrm{O}_{2}\right]$ (Fig. S9, ESI $\dagger$ ). However, the uncertainty in the ion-trap pressure ultimately 
Table 2 Second-order rate coefficients $\left(k_{2 n d}, \mathrm{~cm}^{3}\right.$ molecule $\left.{ }^{-1} \mathrm{~s}^{-1}\right)$ and reaction efficiencies $(\Phi \%)$ for reactions of PD generated distonic radical cations with $\mathrm{O}_{2}$ (molecule $\mathrm{cm}^{-3}$ ). Uncertainties are an estimated upper limit of $50 \%$ in second-order rate coefficients and reaction efficiencies. $\mathrm{O}_{2}$ collision frequencies calculated using the Langevin collision model ${ }^{39}$

\begin{tabular}{|c|c|c|c|c|}
\hline Distonic radical & {$\left[\mathrm{O}_{2}\right]\left(\right.$ molecule $\left.\mathrm{cm}^{-3}\right)$} & $k_{2 \text { nd }}\left(\mathrm{cm}^{3}\right.$ molecule $\left.{ }^{-1} \mathrm{~s}^{-1}\right)$ & $\begin{array}{l}\text { Collision frequency } \\
\left(\mathrm{cm}^{3} \text { molecule }^{-1} \mathrm{~s}^{-1}\right)\end{array}$ & $\Phi(\%)$ \\
\hline 5-Ammonium-2-hydroxyphenyl & Low $\left[10^{9}\right]$ & $2.9 \times 10^{-11}$ & $5.9 \times 10^{-10}$ & 4.9 \\
\hline 5-(N,N,N-Trimethylammonium)-2-hydroxyphenyl & $6.6 \times 10^{9}$ & $2.5 \times 10^{-11}$ & $5.7 \times 10^{-10}$ & 4.4 \\
\hline 5-(N,N,N-Trimethylammonium)-2-methylphenyl ${ }^{a}$ & $\begin{array}{l}2.2 \times 10^{9} \\
8.5 \times 10^{9}\end{array}$ & $\begin{array}{l}2.9 \times 10^{-11} \\
2.6 \times 10^{-11}\end{array}$ & $5.7 \times 10^{-10}$ & $\begin{array}{l}5.1 \\
4.5\end{array}$ \\
\hline
\end{tabular}

${ }^{a}$ Rate coefficients reported in ref. 17. Ions of $m / z 149$ were generated by PD of the 3-bromo- $N, N, N, 4$-trimethylbenzenaminium cation.

results in an upper limit of $50 \%$ uncertainty in the trap $\left[\mathrm{O}_{2}\right]$, and consequently, a $50 \%$ uncertainty for the reported secondorder rate coefficients and reaction efficiencies in Table 2.

Reaction efficiencies for all species reported in Table 2 are all approximately equal to $5 \%$, similar to reported reaction efficiencies for neutral phenyl radicals and a range of positively charged distonic phenyl radical ions, including trimethylammonium and pyridinium-tagged phenyl radicals, ${ }^{27}$ and distonic $o$-methylphenyl radicals. ${ }^{17}$ For the 5-ammonium-2-hydroxyphenyl + $\mathrm{O}_{2}$ reaction mechanism discussed further below, proximity of the ortho-OH-substituent to the peroxyl-radical site in the $o$-hydroxyphenylperoxyl radical provides a notably low-energy reaction pathway (refer to Fig. 6) that competes with dissociation of the peroxyl radical intermediate toward separated reactants, however, it does not appear to significantly affect measured reaction efficiencies compared to the other values reported in Table 2 and for the phenyl-type radical $+\mathrm{O}_{2}$ reactions cited above. This moderate reaction efficiency of $\sim 5 \%$, consistent for a range of phenyl-type radicals, ${ }^{17,27}$ indicates that the rate of reaction is not controlled by the microcanonical rate for forward dissociation pathways. Instead, it may result from an entropic bottleneck after formation of the non-covalent complex between the phenyl radical and $\mathrm{O}_{2}$ (ref. 65-67) that reflects reaction flux back to the free reactants. More experiments and insights are required to address this question.

\subsection{Reaction mechanism}

3.3.1 $o$-Hydroxyphenyl $+\mathrm{O}_{2} \rightarrow o$-BQ $+\mathbf{O H}$. To assist in rationalising the experimental data, enthalpies of key reaction intermediates and transition states were calculated for the neutral and ammonium-tagged $o$-hydroxyphenyl $+\mathrm{O}_{2}$ systems using the G3X-K method. ${ }^{40}$ The potential energy schematic in Fig. 6 shows $\mathrm{O}_{2}$ addition, 1,5-H-transfer and subsequent $\mathrm{OH}$ elimination to produce the neutral (scheme shown in black) and charge-tagged $o$-BQ (shown in blue). Potential energy schemes for other possible reaction processes, including those involving the hydroxyl-substituted oxepinoxyl radical intermediate, are also discussed below and provided in the ESI $\dagger$ (Fig. 8 and Fig. S12-S15).

Addition of $\mathrm{O}_{2}$ to the neutral $o$-hydroxyphenyl radical produces the $o$-hydroxyphenylperoxyl radical species (N2) that is $49.0 \mathrm{kcal} \mathrm{mol}^{-1}$ below the energy of separated reactants (N1), as shown in Fig. 6. Close proximity of the $\mathrm{OH}$ substituent to the

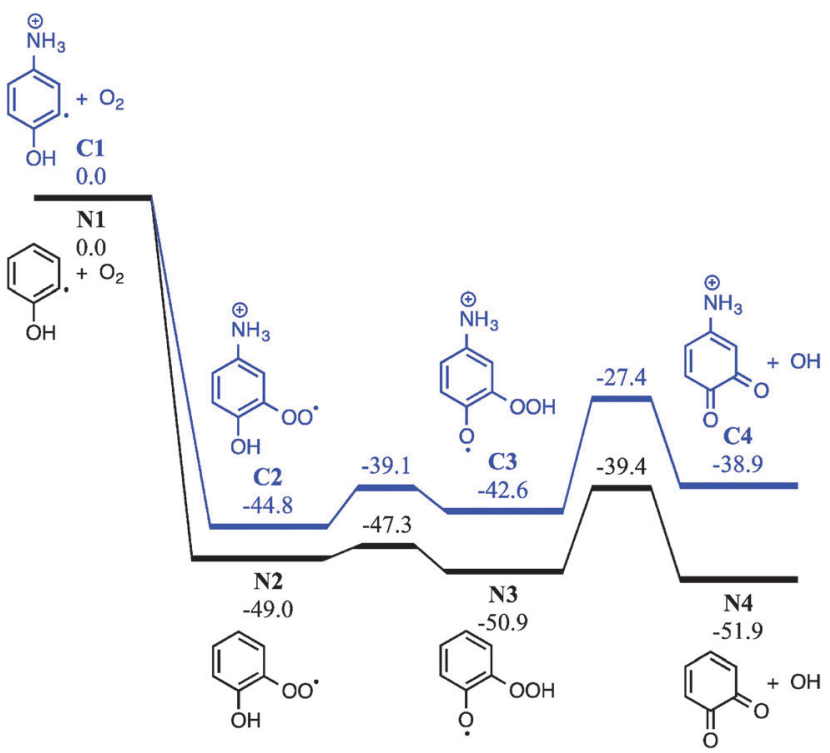

Fig. 6 Potential energy schematic depicting the peroxyl $\rightarrow$ hydroperoxy radical isomerisation and subsequent $\mathrm{OH}$ elimination for both neutral (black) and ammonium-tagged (blue) o-hydroxyphenyl $+\mathrm{O}_{2}$. G3X-K $0 \mathrm{~K}$ enthalpies are provided in $\mathrm{kcal} \mathrm{mol}^{-1}$ relative to the respective o-hydroxyphenyl $+\mathrm{O}_{2}$ reactants.

peroxyl radical site in the $o$-hydroxyphenylperoxyl radical (N2) allows for a 1,5-H shift via TS N2 $\rightarrow \mathbf{N} 3$ with an incredibly small $1.7 \mathrm{kcal} \mathrm{mol}^{-1}$ barrier to the $o$-hydroperoxyphenoxyl radical (N3). Elimination of $\mathrm{OH}$ from the hydroperoxyl group in $\mathbf{N} 3$ via TS N3 $\rightarrow$ N4 (11.5 kcal mol ${ }^{-1}$ barrier) results in $o-\mathrm{BQ}+\mathrm{OH}$ with a reaction exothermicity of $51.9 \mathrm{kcal} \mathrm{mol}^{-1}$. Comparing this to the charge-tagged case, the $o$-hydroxyphenylperoxyl radical analogue (C2) is $44.8 \mathrm{kcal} \mathrm{mol}^{-1}$ below the energy of the separated reactants (C1). The barrier to the 1,5- $\mathrm{H}$ shift in $\mathbf{C} 2$ and subsequent $\mathrm{OH}$ loss from $\mathbf{C} 3$ is $27.4 \mathrm{kcal} \mathrm{mol}^{-1}$ below reactants and the resulting 4-ammonium-2-benzoquinone $+\mathrm{OH}(\mathbf{C 4})$ products are formed with an exothermicity of $38.9 \mathrm{kcal} \mathrm{mol}^{-1}\left(13.0 \mathrm{kcal} \mathrm{mol}^{-1}\right.$ less than in the neutral case). As shown by Fig. S10 in the ESI, $\dagger$ the reaction enthalpy for charge-tagged $o-\mathrm{BQ}+\mathrm{OH}$ is reduced by separation of the charge tag and ring structure via inclusion of methylene linkages, indicating that differences shown in Fig. 6 are (in part) due to a through-space charge effect. Still, intermediates and transition states for both cases shown in Fig. 6 are well below the energy of the reactants and, therefore, 
$\mathrm{OH}$-elimination is expected to be facile. This mechanism is consistent with the appearance of $o$-BQ $(\mathrm{m} / \mathrm{z} 108)$ in neutral flow-tube experiments and ammonium-tagged $o$-BQ $(\mathrm{m} / \mathrm{z} 124)$ in the distonic radical cation experiments.

3.3.2 $\mathrm{o}$-BQ $\rightarrow \mathbf{C P O}+\mathbf{C O}$. The appearance of signal at $\mathrm{m} / \mathrm{z} 80$ in the ALS neutral experiments is rationalised by prompt CO elimination from $o$-BQ $(m / z 108)^{21}$ and is supported by distonic radical cation experiments (Fig. $4 \mathrm{c}$ and d). The potential energy schematic for CO elimination from $o$-BQ is provided in Fig. 7 and Fig. S11 (ESI $\dagger$ ) for the charge-tagged case, with reaction enthalpies reported relative to the $o$-BQ species. Shown in Fig. 7, the pathway via $\mathbf{N} 7$ has the lower barrier of $41.9 \mathrm{kcal} \mathrm{mol}^{-1}$ $\left(-10.0 \mathrm{kcal} \mathrm{mol}{ }^{-1}\right.$ relative to $o$-hydroxyphenyl $\left.+\mathrm{O}_{2}\right)$. An alternate mechanism via TS N6 $\rightarrow$ N8 (ref. 68) has a higher $43.5 \mathrm{kcal} \mathrm{mol}^{-1}$ barrier. A transition state for concerted CO loss was located with a $62.6 \mathrm{kcal} \mathrm{mol}^{-1}$ barrier, $10.7 \mathrm{kcal} \mathrm{mol}^{-1}$ in excess of the $o$-hydroxyphenyl $+\mathrm{O}_{2}$ entrance channel (not shown). The CPO + $\mathrm{CO}+\mathrm{OH}$ product is $45.5 \mathrm{kcal} \mathrm{mol}^{-1}$ below the energy of the $o$-hydroxyphenyl $+\mathrm{O}_{2}$ reactants.

Fig. S11 (ESI $\dagger$ ) shows the potential energy scheme for CO elimination from ammonium-tagged $o$-BQ. The mechanisms shown in Fig. S11a (ESI $\dagger$ ) feature barriers that exceed the entrance channel (5-ammonium-2-hydroxyphenyl $+\mathrm{O}_{2}$ ) by $2.8 \mathrm{kcal} \mathrm{mol}^{-1}$ via TS C6a $\rightarrow$ C8 and $6.7 \mathrm{kcal} \mathrm{mol}^{-1}$ via TS C6b $\rightarrow$ C8. In Fig. S11b (ESI $\dagger$ ), however, the highest barrier is $35.0 \mathrm{kcal} \mathrm{mol}{ }^{-1}$ via TS $\mathbf{C 4} \rightarrow \mathbf{C 5}\left(3.8 \mathrm{kcal} \mathrm{mol}^{-1}\right.$ below 5-ammonium-2-hydroxyphenyl $+\mathrm{O}_{2}$ ). The decomposition reactions shown in Fig. S11 (ESI $\dagger$ ) are less likely to proceed due to the reduced exothermicity of the charge-tagged $o-\mathrm{BQ}+\mathrm{OH}$ and barriers to decarbonylation approaching the entrance channel limit. Collisional activation of the charge-tagged $o$-BQ intermediate should provide the activation energy required to generate charge-tagged CPO + CO, consistent with a loss of 28 Da from CID of $m / z 124$ ions shown in Fig. 4c. The appearance of a small $m / z 96$ ion peak in Fig. $4 \mathrm{~b}(<1 \%)$, prior to isolation of the $\mathrm{m} / \mathrm{z} 124$ ion, may result from decomposition of the high-energy portion of the nascent $m / z 124$ ion ensemble. It is likely that further exploration of $o$-BQ decomposition is required to reveal additional competitive pathways resulting in $\mathrm{CPO}+\mathrm{CO}$.

3.3.3 OH-substituted phenoxyl and oxepinoxyl mechanisms. In the case of unsubstituted phenyl radical oxidation, the direct phenoxyl $+\mathrm{O}\left({ }^{3} \mathrm{P}\right)$ channel and the indirect oxepinoxyl radical decomposition pathways can lead to $\mathrm{CHO}, \mathrm{CO}, \mathrm{O}$, and $\mathrm{H}$ losses to produce CPO and $o$-BQ. ${ }^{59,60,62,69-71}$ To explore the possible role of phenoxyl and oxepinoxyl pathways here, analogous hydroxy-substituted intermediates and transition states were located along the neutral $o$-hydroxyphenyl and 4-ammonium-2hydroxyphenyl radical oxidation schemes. Potential energy schematics are provided in the ESI $\dagger$ (Fig. 8 and Fig. S12-S15). The $\mathrm{O}\left({ }^{3} \mathrm{P}\right)$ loss from hydroxyphenylperoxyl has a $30.6 \mathrm{kcal} \mathrm{mol}^{-1}$ barrier and subsequent decomposition of the $o$-hydroxyphenoxyl radical (N40, Fig. S12, ESI $\dagger$ ) to produce CPO occurs via stationary points that exceed $o$-hydroxyphenyl $+\mathrm{O}_{2}$ by as much as $61.1 \mathrm{kcal} \mathrm{mol}^{-1}$ (TS N43 $\rightarrow \mathbf{N 4 4}$ ). In the charge-tagged case, $\mathrm{O}\left({ }^{3} \mathrm{P}\right)$ loss occurs with a $32.0 \mathrm{kcal} \mathrm{mol}^{-1}$ barrier (inset Fig. S12, ESI $\dagger$ ) and the overall barrier to 3-ammonium-cyclopentadienone $+\mathrm{H}+\mathrm{CO}+\mathrm{O}\left({ }^{3} \mathrm{P}\right)$ is $69.9 \mathrm{kcal} \mathrm{mol}^{-1}$ above the reactants. These high reaction barriers are unlikely to compete with lower energy pathways. As previously mentioned in Section 3.1 above, small quantities of $o$-hydroxyphenoxyl radicals are likely generated and later react by $\mathrm{H}$-atom addition to produce $o$-catechol $\left(\mathrm{C}_{6} \mathrm{H}_{4} \mathrm{OHOH}, \mathrm{m} / \mathrm{z}\right.$ 110). These data together indicate that generation of CPO from $o$-hydroxyphenoxyl radicals is unlikely.

Rearrangement of $o$-hydroxyphenylperoxyl (N2) toward 7-hydroxyoxepinoxyl (N23) and 6-carboxy-1-oxo-hex-2,4-dienyl radicals (N21) via dioxirane-hydroxycyclohexadienyl intermediates are described in Fig. 8. The reactions of these intermediates represent plausible unimolecular pathways to both $\mathrm{m} / \mathrm{z} 80$ and 108 ions in the ALS experiments. Reactions toward the 7-hydroxyoxepinoxyl radical proceeds through TS N2 $\rightarrow \mathbf{N 2 2} 18.1 \mathrm{kcal} \mathrm{mol}^{-1}$ above the barrier to $o$-BQ (TS N3 $\rightarrow$ N4 in Fig. 6) with an exothermicity of $102.3 \mathrm{kcal} \mathrm{mol}^{-1}$. Formation of the 6-carboxy1-oxo-hex-2,4-dienyl radical (N21) occurs via TS N2 $\rightarrow$ N20 at $11.6 \mathrm{kcal} \mathrm{mol}^{-1}$ above $\mathbf{T S} \mathbf{N} 3 \rightarrow \mathbf{N} 4$. Reactions of chargedtagged $o$-hydroxyphenylperoxyl toward hydroxyoxepinoxyl and 6-carboxyoxohexdienyl, shown in Fig. S13 (ESI $\dagger$ ), generally parallel those described by Fig. 8. The rate limiting steps toward the two hydroxyoxepinoxyl (TS3c) and carboxyoxohexdienyl radicals (TS1c) are 22.2 and $5.1 \mathrm{kcal} \mathrm{mol}^{-1}$, respectively, above the barrier to charge-tagged $o$-BQ (TS C3 $\rightarrow$ C4, Fig. 6).

In the case where either hydroxyoxepinoxyl or carboxyoxohexdienyl radicals are produced, their decomposition could possibly follow pathways described by Fig. S14 and S15 (ESI $\dagger$ ). Likely products, by analogy to phenyl radical oxidation, ${ }^{16,61}$

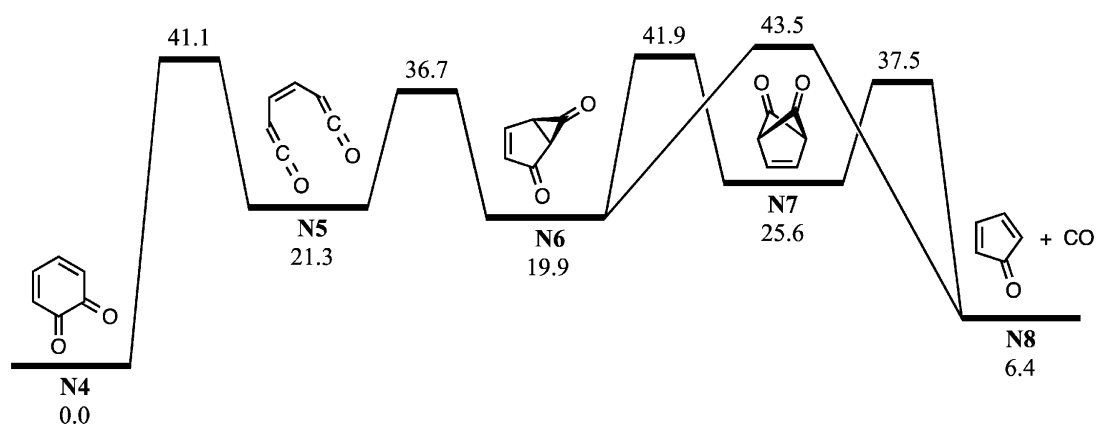

Fig. 7 Potential energy schematic for $\mathrm{CO}$ loss from o-BQ (N4) along the singlet $\mathrm{C}_{6} \mathrm{H}_{4} \mathrm{O}_{2}$ surface. G3X-K 0 K enthalpies are provided in kcal mol ${ }^{-1}$ relative to $\mathrm{O}-\mathrm{BQ}$. 


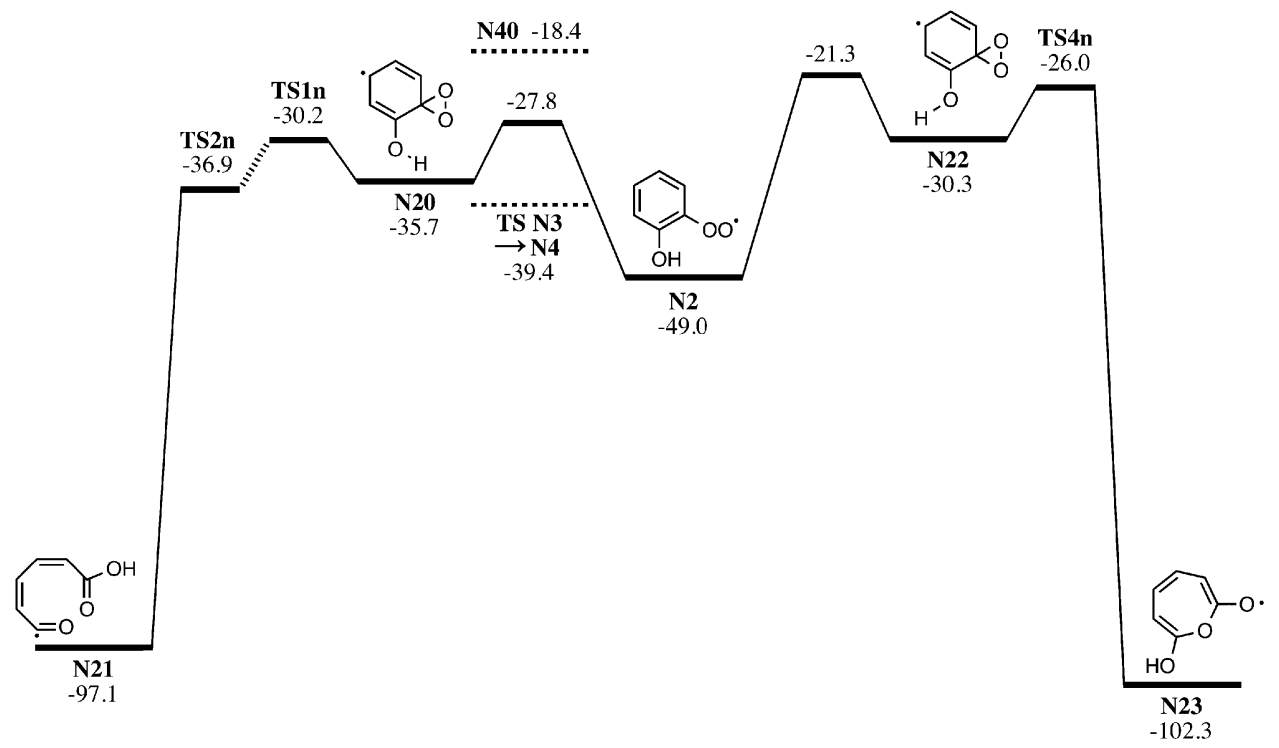

Fig. 8 Potential energy schematic comparing the $\mathrm{OH}$-cis and $\mathrm{OH}$-trans reaction pathways to the hydroxyoxepinoxyl and 6-carboxy-1-oxo-hex-2,4dienyl intermediates along the neutral o-hydroxyphenyl $+\mathrm{O}_{2}$ reaction surface. The barrier to TS N3 $\rightarrow$ N4 (leading to o-BQ) and reaction enthalpy for the o-hydroxyphenoxyl radical (N40) are included for comparison. G3X-K energies are reported in $\mathrm{kcal} \mathrm{mol}^{-1}$ relative to o-hydroxyphenyl $+\mathrm{O}_{2}$.

include $o$-BQ $+\mathrm{OH}, \mathrm{CPO}+\mathrm{HOCO}, 3$-hydroxy-2-benzoquinone + $\mathrm{H}$, and 2-hydroxy-cyclopentadienone + HCO with barriers far below the reactants. The absence of peaks at $\mathrm{m} / \mathrm{z} 96$ and 124 within ALS experimental results (Fig. 1) and the high barriers to hydroxyoxepinoxyl and carboxyoxohexdienyl intermediates indicate that at most only a small fraction of the reaction flux follows these channels. Furthermore, preliminary RRKM modelling of the $o$-hydroxyphenylperoxyl radical (N2) decomposition, utilizing MultiWell, ${ }^{45}$ indicates $\mathrm{H}$-migration and $\mathrm{OH}$-loss to form $o$-BQ (N4, shown in Fig. 6) comprehensively outcompetes the pathways toward hydroxyoxepinoxyl and carboxyoxohexadienyl radicals (shown in Fig. 8, N2 toward TS1n and TS4n). The sums of states for salient transition states and corresponding rate coefficients are provided in Table S2 (ESI $\dagger$ ). The oxepinoxyl pathways (via TS1n and TS4n) experience comparatively tight transition states with state counts several orders of magnitude lower than any other along the $o$-BQ pathway. This is in accord with our previous statement that the prevailing mechanism is formation of $o$-BQ via an $o$-hydroxyperoxylphenoxyl radical intermediate (N3). The appearance of $\mathrm{m} / \mathrm{z} 80$ in ALS experiments is explained by $o$-BQ decomposition, supported by distonic experiments that show connectivity between the analogous charge-tagged species.

\section{Conclusions}

Product detection experiments conducted at the ALS synchrotron reveal that the $o$-hydroxyphenyl $+\mathrm{O}_{2}$ reaction produces two major products detected at $\mathrm{m} / \mathrm{z} 80$ and 108 that are consistent with CPO and $o$-BQ. We conclude that CPO forms as a secondary product from prompt decomposition of $o-\mathrm{BQ}$ and dissociative ionisation of $o$-BQ leads to some enhancement of the $\mathrm{m} / \mathrm{z} 80$ signal at photoionisation energies $\geq 9.8 \mathrm{eV}$. There are indications of a minor $o$-hydroxyphenoxyl $+\mathrm{O}\left({ }^{3} \mathrm{P}\right)$ pathway in the ALS experiments. To establish connections between the major reaction products, distonic radical analogue ammonium-tagged $o$-hydroxyphenyl $+\mathrm{O}_{2}$ reactions were studied using ion-trap mass spectrometry. Reactions of the 5-ammonium-2-hydroxyphenyl radical cation $(m / z 109)$ with $\mathrm{O}_{2}$ produced product ions consistent with ammonium-tagged $o$-BQ produced via $\mathrm{O}_{2}$ addition, $\mathrm{H}$-atom migration and subsequent $\mathrm{OH}$ loss. CID of the $\mathrm{m} / \mathrm{z} 124$ ions yielded a species assigned ammonium-tagged CPO produced by CO loss.

Second order rate coefficients $\left(k_{2 n d}\right)$ for 5-ammonium-2hydroxyphenyl $(m / z 109)+\mathrm{O}_{2}$ were measured to have a $5 \%$ reaction efficiency. Additional kinetic measurements for $\mathrm{O}_{2}$ reactions with $\mathrm{PD}$ generated 5-ammonium-2-methylphenyl and 5 -( $N, N, N$-trimethylammonium)-2-hydroxyphenyl radical cations and a previous investigation of trimethylammonium-tagged $o$-methylphenyl $+\mathrm{O}_{2}$ reaction kinetics ${ }^{17}$ demonstrate for this small set that the identity of the charged-tag and ortho-substituent does not significantly affect the reaction efficiency (ca. 5\%).

Quantum chemical calculations are in accord with our experimental observations, where a $1,5-\mathrm{H}$ shift in the $o$-hydroxyphenylperoxyl adduct and subsequent $\mathrm{OH}$ elimination is the minimum energy pathway for both $o$-hydroxylphenyl $+\mathrm{O}_{2}$ and the ammonium-tagged counterpart. Decomposition of the $o$-BQ toward CPO does encounter large barriers. However, the indication from preliminary kinetic modelling is that production of $o$-BQ is the dominant unimolecular pathway.

The prevailing mechanism for decomposition of the $o$-hydroxyphenylperoxyl radical produced by $\mathrm{O}_{2}$ addition is via $1,5-\mathrm{H}$ migration and $\mathrm{OH}$ loss from the hydroperoxyphenoxyl radical intermediate to produce $o$-BQ. Its decomposition via ring opening, cyclisation, and CO elimination is the likely pathway to CPO. These proposed pathways to $o$-BQ and CPO serve as source of $\mathrm{OH}$ and $\mathrm{CO}$ species in reactive environments. 


\section{Acknowledgements}

The authors are grateful for the financial support of the Australian Research Council through the Discovery programs (SJB: DP140101237; AJT and GdS: DP 130100862; GdS: FT130101304) and Centre of Excellence For Free Radical Chemistry and Biotechnology (CE0561607). The authors also acknowledge the generous allocation of computing resources by the NCI National Facility (Canberra, Australia) under Merit Allocation Scheme. BBK is supported by the National Aeronautics and Space Administration (NNH13AV43I). JDS, DLO, and CAT are supported by the Division of Chemical Sciences, Geosciences, and Biosciences, the Office of Basic Energy Sciences, the U.S. Department of Energy. Sandia is a multi-program laboratory operated by Sandia Corporation, a Lockheed Martin Company, for the National Nuclear Security Administration under contract DE-AC04-94AL85000. This research used resources of the Advanced Light Source, which is a DOE Office of Science User Facility at the Lawrence Berkeley National Laboratory. MBP would like to acknowledge Dr. Phillip J. Tracey for discussions on distonic radical cation experiments.

\section{References}

1 G. Gellerstedt, J. Li, I. Eide, M. Kleinert and T. Barth, Chemical Structures Present in Biofuel Obtained from Lignin, Energy Fuels, 2008, 22, 4240-4244.

2 Y. Huang, H. Sakamoto, S. Kudo, K. Norinaga and J.-i. Hayashi, Pyrolysis of Lignite with Internal Recycling and Conversion of Oil, Energy Fuels, 2014, 28, 7285-7293.

$3 \mathrm{~W}$. W. Focke, I. van der Westhuizen, A. B. L. Grobler, K. T. Nshoane, J. K. Reddy and A. S. Luyt, The Effect of Synthetic Antioxidants on the Oxidative Stability of Biodiesel, Fuel, 2012, 94, 227-233.

4 N. A. Santos, A. M. T. M. Cordeiro, S. S. Damasceno, R. T. Aguiar, R. Rosenhaim, J. R. Carvalho Filho, I. M. G. Santos, A. S. Maia and A. G. Souza, Commercial Antioxidants and Thermal Stability Evaluations, Fuel, 2012, 97, 638-643.

5 S. Schober and M. Mittelbach, The Impact of Antioxidants on Biodiesel Oxidation Stability, Eur. J. Lipid Sci. Technol., 2004, 106, 382-389.

6 B. D. Batts and A. Z. Fathoni, A Literature Review on Fuel Stability Studies with Particular Emphasis on Diesel Oil, Energy Fuels, 1991, 5, 2-21.

7 S. Lomnicki, H. Truong and B. Dellinger, Mechanisms of Product Formation from the Pyrolytic Thermal Degradation of Catechol, Chemosphere, 2008, 73, 629-633.

8 E. Bjergbakke, A. Sillesen and P. Pagsberg, UV Spectrum and Kinetics of Hydroxycyclohexadienyl Radicals, J. Phys. Chem., 1996, 100, 5729-5736.

9 C. Venkat, K. Brezinsky and I. Glassman, High Temperature Oxidation of Aromatic Hydrocarbons, Proc. Combust. Inst., 1982, 19, 143-152.

10 G. da Silva, M. R. Hamdan and J. W. Bozzelli, Oxidation of the Benzyl Radical: Mechanism, Thermochemistry, and Kinetics for the Reactions of Benzyl Hydroperoxide, J. Chem. Theory Comput., 2009, 5, 3185-3194.

11 A. M. Scheer, C. Mukarakate, D. J. Robichaud, M. R. Nimlos, H.-H. Carstensen and G. Barney Ellison, Unimolecular Thermal Decomposition of Phenol and D5-Phenol: Direct Observation of Cyclopentadiene Formation Via Cyclohexadienone, J. Chem. Phys., 2012, 136, 044309.

12 Y. Z. He, W. G. Mallard and W. Tsang, Kinetics of Hydrogen and Hydroxyl Radical Attack on Phenol at High Temperatures, J. Phys. Chem., 1988, 92, 2196-2201.

13 T. Berndt and O. Boge, Gas-Phase Reaction of $\mathrm{OH}$ Radicals with Phenol, Phys. Chem. Chem. Phys., 2003, 5, 342-350.

14 R. Atkinson, Kinetics and Mechanisms of the Gas-Phase Reactions of the Hydroxyl Radical with Organic Compounds, J. Phys. Chem. Ref. Data, 1989, Monograph No. 1, 246.

15 D. J. Robichaud, A. M. Scheer, C. Mukarakate, T. K. Ormond, G. T. Buckingham, G. B. Ellison and M. R. Nimlos, Unimolecular Thermal Decomposition of Dimethoxybenzenes, J. Chem. Phys., 2014, 140, 234302.

16 G. da Silva, C.-C. Chen and J. W. Bozzelli, Toluene Combustion: Reaction Paths, Thermochemical Properties, and Kinetic Analysis for the Methylphenyl Radical $+\mathrm{O}_{2}$ Reaction, J. Phys. Chem. A, 2007, 111, 8663-8676.

17 M. B. Prendergast, P. A. Cooper, B. B. Kirk, G. da Silva, S. J. Blanksby and A. J. Trevitt, Hydroxyl Radical Formation in the Gas Phase Oxidation of Distonic 2-Methylphenyl Radical Cations, Phys. Chem. Chem. Phys., 2013, 15, 20577-20584.

18 D. C. DeJongh, R. Y. Van Fossen and C. F. Bourgeois, Comparative Studies of Electron-Impact and Thermolytic Fragmentation. II. o-Phenylene Sulfite, Tetrahedron Lett., 1967, 8, 271-276.

19 D. DeJongh and D. Brent, Mass Spectra and Pyrolyses of o-Phenylene Carbonate and Related Compounds, J. Org. Chem., 1970, 35, 4204-4208.

20 O. L. Chapman and C. L. McIntosh, Cyclopentadienone, J. Chem. Soc. D, 1971, 770-771.

21 T. K. Ormond, A. M. Scheer, M. R. Nimlos, D. J. Robichaud, T. P. Troy, M. Ahmed, J. W. Daily, T. L. Nguyen, J. F. Stanton and G. B. Ellison, Pyrolysis of Cyclopentadienone: Mechanistic Insights from a Direct Measurement of Product Branching Ratios, J. Phys. Chem. A, 2015, 119, 7222-7234.

22 B. N. Moore, S. J. Blanksby and R. R. Julian, Ion-Molecule Reactions Reveal Facile Radical Migration in Peptides, Chem. Commun., 2009, 5015-5017.

23 D. J. M. Ray, A. Redfearn and D. J. Waddington, Gas-Phase Oxidation of Alkenes: Decomposition of HydroxySubstituted Peroxyl Radicals, J. Chem. Soc., Perkin Trans. 2, 1973, 540-543.

24 D. J. M. Ray and D. J. Waddington, Gas Phase Oxidation of Alkenes-Part II. The Oxidation of 2-Methylbutene-2 and 2,3-Dimethylbutene-2, Combust. Flame, 1973, 20, 327-334.

25 O. Welz, J. Zádor, J. D. Savee, L. Sheps, D. L. Osborn and C. A. Taatjes, Low-Temperature Combustion Chemistry of $N$-Butanol: Principal Oxidation Pathways of Hydroxybutyl Radicals, J. Phys. Chem. A, 2013, 117, 11983-12001. 
26 P. E. Williams, B. J. Jankiewicz, L. Yang and H. I. Kenttämaa, Properties and Reactivity of Gaseous Distonic Radical Ions with Aryl Radical Sites, Chem. Rev., 2013, 113, 6949-6985.

27 B. B. Kirk, D. G. Harman, H. I. Kenttämaa, A. J. Trevitt and S. J. Blanksby, Isolation and Characterization of ChargeTagged Phenylperoxyl Radicals in the Gas Phase: Direct Evidence for Products and Pathways in Low Temperature Benzene Oxidation, Phys. Chem. Chem. Phys., 2012, 14, 16719-16730.

28 D. L. Osborn, P. Zou, H. Johnsen, C. C. Hayden, C. A. Taatjes, V. D. Knyazev, S. W. North, D. S. Peterka, M. Ahmed and S. R. Leone, The Multiplexed Chemical Kinetic Photoionization Mass Spectrometer: A New Approach to Isomer-Resolved Chemical Kinetics, Rev. Sci. Instrum., 2008, 79, 104103.

29 A. G. Suits, P. Heimann, X. Yang, M. Evans, C.-W. Hsu, K.-t. Lu, Y. T. Lee and A. H. Kung, A Differentially Pumped Harmonic Filter on the Chemical Dynamics Beamline at the Advanced Light Source, Rev. Sci. Instrum., 1995, 66, 4841-4844.

30 S. R. Leone, M. Ahmed and K. R. Wilson, Chemical Dynamics, Molecular Energetics, and Kinetics at the Synchrotron, Phys. Chem. Chem. Phys., 2010, 12, 6564-6578.

31 D. P. Biddiscombe and J. F. Martin, Vapour Pressures of Phenol and the Cresols, Trans. Faraday Soc., 1958, 54, 1316-1322.

32 Normalised collision energy is a term used by the instrument vendor as explained here: https://static.thermoscienti fic.com/images/D13507 .pdf. Zero, on this scale, means that no additional resonant excitation is applied.

33 T.-Y. Kim, M. S. Thompson and J. P. Reilly, Peptide Photodissociation at $157 \mathrm{Nm}$ in a Linear Ion Trap Mass Spectrometer, Rapid Commun. Mass Spectrom., 2005, 19, 1657-1665.

34 T. Ly and R. R. Julian, Residue-Specific Radical-Directed Dissociation of Whole Proteins in the Gas Phase, J. Am. Chem. Soc., 2008, 130, 351-358.

35 T. Ly, B. B. Kirk, P. I. Hettiarachchi, B. L. J. Poad, A. J. Trevitt, G. da Silva and S. J. Blanksby, Reactions of Simple and Peptidic Alpha-Carboxylate Radical Anions with Dioxygen in the Gas Phase, Phys. Chem. Chem. Phys., 2011, 13, 16314-16323.

36 C. S. Hansen, B. B. Kirk, S. J. Blanksby, R. A. J. O'Hair and A. J. Trevitt, UV Photodissociation Action Spectroscopy of Haloanilinium Ions in a Linear Quadrupole Ion Trap Mass Spectrometer, J. Am. Soc. Mass Spectrom., 2013, 24, 932-940.

37 D. G. Harman and S. J. Blanksby, Investigation of the Gas Phase Reactivity of the 1-Adamantyl Radical Using a Distonic Radical Anion Approach, Org. Biomol. Chem., 2007, 5, 3495-3503.

38 W. A. Donald, G. N. Khairallah and R. A. J. O'Hair, The Effective Temperature of Ions Stored in a Linear Quadrupole Ion Trap Mass Spectrometer, J. Am. Soc. Mass Spectrom., 2013, 24, 811-815.

39 P. Langevin, A Fundamental Formula of Kinetic Theory, Ann. Chim. Phys., 1905, 5, 245.

40 G. da Silva, G3X-K Theory: A Composite Theoretical Method for Thermochemical Kinetics, Chem. Phys. Lett., 2013, 558, 109-113.
41 M. J. Frisch, G. W. Trucks, H. B. Schlegel, G. E. Scuseria, M. A. Robb, J. R. Cheeseman, G. Scalmani, V. Barone, B. Mennucci, G. A. Petersson, H. Nakatsuji, M. Caricato, X. Li, H. P. Hratchian, A. F. Izmaylov, J. Bloino, G. Zheng, J. L. Sonnenberg, M. Hada, M. Ehara, K. Toyota, R. Fukuda, J. Hasegawa, M. Ishida, T. Nakajima, Y. Honda, O. Kitao, H. Nakai, T. Vreven, J. A. Montgomery, J. E. Peralta, F. Ogliaro, M. Bearpark, J. J. Heyd, E. Brothers, K. N. Kudin, V. N. Staroverov, R. Kobayashi, J. Normand, K. Raghavachari, A. Rendell, J. C. Burant, S. S. Iyengar, J. Tomasi, M. Cossi, N. Rega, J. M. Millam, M. Klene, J. E. Knox, J. B. Cross, V. Bakken, C. Adamo, J. Jaramillo, R. Gomperts, R. E. Stratmann, O. Yazyev, A. J. Austin, R. Cammi, C. Pomelli, J. W. Ochterski, R. L. Martin, K. Morokuma, V. G. Zakrzewski, G. A. Voth, P. Salvador, J. J. Dannenberg, S. Dapprich, A. D. Daniels, Ö. Farkas, J. B. Foresman, J. V. Ortiz, J. Cioslowski and D. J. Fox, Gaussian 09, 2009.

42 J. Zheng, Y. Zhao and D. G. Truhlar, The DBH24/08 Database and Its Use to Assess Electronic Structure Model Chemistries for Chemical Reaction Barrier Heights, J. Chem. Theory Comput., 2009, 5, 808-821.

43 J. A. Montgomery, M. J. Frisch, J. W. Ochterski and G. A. Petersson, A Complete Basis Set Model Chemistry. VI. Use of Density Functional Geometries and Frequencies, J. Chem. Phys., 1999, 110, 2822-2827.

44 J. A. Montgomery, M. J. Frisch, J. W. Ochterski and G. A. Petersson, A Complete Basis Set Model Chemistry. VII. Use of the Minimum Population Localization Method, J. Chem. Phys., 2000, 112, 6532-6542.

45 (a) MultiWell-2013.1 Software, designed and maintained by John R. Barker with contributors N. F. Ortiz, J. M. Preses, L. L. Lohr, A. Maranzana, P. J. Stimac, T. Lam Nguyen, and T. J. Dhilip Kumar; University of Michigan, Ann Arbor, MI; http://aoss.engin.umich.edu/multiwell/; $(b)$ J. R. Barker, Int. J. Chem. Kinet., 2001, 33, 232-245; (c) J. R. Barker, Int. J. Chem. Kinet., 2009, 41, 748-763.

46 R. Schulz and A. Schweig, Elucidation of Thermal Reactions by Variable Temperature Photoelectron Spectral Detection of Reactive Intermediates. The UV Photoelectron Spectra of Transient Fulveneketene, Fulvenethioketene, A Ketoketene and Thiobenzpropiolactone, Tetrahedron Lett., 1979, 20, 59-62.

47 H. Bock, T. Hirabayashi and S. Mohmand, GasphasenReaktionen, 21. Thermische Erzeugung Von Alkyl- Und Halogenketenen, Chem. Ber., 1981, 114, 2595-2608.

48 S. G. Lias, R. D. Levin and S. A. Kafafi, in NIST Chemistry Webbook, NIST Standard Reference Database Number 69, ed. P. J. Linstrom and W. G. Mallard, National Institute of Standards and Technology, Gaithersburg MD, 20899, 2011.

49 C. A. Taatjes, D. L. Osborn, T. M. Selby, G. Meloni, A. J. Trevitt, E. Epifanovsky, A. I. Krylov, B. Sirjean, E. Dames and H. Wang, Products of the Benzene $+\mathrm{O}\left({ }^{3} \mathrm{P}\right)$ Reaction, J. Phys. Chem. A, 2010, 114, 3355-3370.

50 K. Fuke, H. Yoshiuchi, K. Kaya, Y. Achiba, K. Sato and K. Kimura, Multiphoton Ionization Photoelectron Spectroscopy 
and Two-Color Multiphoton Ionization Threshold Spectroscopy on the Hydrogen Bonded Phenol and 7-Azaindole in a Supersonic Jet, Chem. Phys. Lett., 1984, 108, 179-184.

51 S. G. Lias, J. E. Bartmess, J. F. Liebman, J. L. Holmes, R. D. Levin and W. G. Mallard, in NIST Chemistry Webbook, NIST Standard Reference Database Number 69, ed. P. J. Linstrom and W. G. Mallard, National Institute of Standards and Technology, Gaithersburg MD, 20899, 2011.

52 N. Akai, S. Kudoh, M. Takayanagi and M. Nakata, Photoreaction Mechanisms of 2-Bromophenols Studied by LowTemperature Matrix-Isolation Infrared Spectroscopy and Density-Functional-Theory Calculation, Chem. Phys. Lett., 2002, 363, 591-597.

53 T. K. Ormond, P. Hemberger, T. P. Troy, M. Ahmed, J. F. Stanton and G. B. Ellison, The Ionisation Energy of Cyclopentadienone: A Photoelectron-Photoion Coincidence Study, Mol. Phys., 2015, 113, 2350-2358.

54 J. Yang, Photonionization Cross Section Database, Center for Advanced Combustion and Energy, 2011.

55 D. S. N. Parker, R. I. Kaiser, T. P. Troy, O. Kostko, M. Ahmed and A. M. Mebel, Toward the Oxidation of the Phenyl Radical and Prevention of PAH Formation in Combustion Systems, J. Phys. Chem. A, 2015, 119, 7145-7154.

56 V. K. Potapov and V. V. Sorokin, Photoionization and IonMolecule Reactions in Quinones and Alcohols, High Energy Chem., 1971, 5, 435.

57 M. H. Palmer, W. Moyes, M. Speirs and J. N. A. Ridyard, The Electronic Structure of Substituted Benzenes; $\mathrm{Ab}$ Initio Calculations and Photoelectron Spectra for Phenol, the Methyl- and Fluoro-Derivatives, and the Dihydroxybenzenes, J. Mol. Struct., 1979, 52, 293-307.

58 Y. Pan, L. Zhang, T. Zhang, H. Guo, X. Hong and F. Qi, Photoionization Studies on Various Quinones by an Infrared Laser Desorption/Tunable VUV Photoionization Tof Mass Spectrometry, J. Mass Spectrom., 2008, 43, 1701-1710.

59 B. K. Carpenter, Computational Prediction of New Mechanisms for the Reactions of Vinyl and Phenyl Radicals with Molecular Oxygen, J. Am. Chem. Soc., 1993, 115, 9806-9807.

60 M. J. Fadden, C. Barckholtz and C. M. Hadad, Computational Study of the Unimolecular Decomposition Pathways of Phenylperoxy Radical, J. Phys. Chem. A, 2000, 104, 3004-3011.

61 M. J. Fadden and C. M. Hadad, Unimolecular Decomposition of the 2-Oxepinoxy Radical: A Key Seven-Membered Ring Intermediate in the Thermal Oxidation of Benzene, J. Phys. Chem. A, 2000, 104, 8121-8130.

62 I. V. Tokmakov, G.-S. Kim, V. V. Kislov, A. M. Mebel and M. C. Lin, The Reaction of Phenyl Radical with Molecular Oxygen: A G2M Study of the Potential Energy Surface, J. Phys. Chem. A, 2005, 109, 6114-6127.

63 B. B. Kirk, D. G. Harman and S. J. Blanksby, Direct Observation of the Gas Phase Reaction of the Cyclohexyl Radical with Dioxygen Using a Distonic Radical Ion Approach, J. Phys. Chem. A, 2010, 114, 1446-1456.

64 C. H. Li, G. N. Khairallah, A. K. Y. Lam, R. A. J. O’Hair, B. B. Kirk, S. J. Blanksby, G. da Silva and U. Wille, Reaction of Aromatic Peroxyl Radicals with Alkynes: A Mass Spectrometric and Computational Study Using the Distonic Radical Ion Approach, Chem. - Asian J., 2013, 8, 450-464.

65 G. da Silva and J. W. Bozzelli, Variational Analysis of the Phenyl $+\mathrm{O}_{2}$ and Phenoxy $+\mathrm{O}$ Reactions, J. Phys. Chem. A, 2008, 112, 3566-3575.

$66 \mathrm{~J}$. J. Casero and J. A. Joens, Thermochemistry of Gas-Phase Molecular Complexes of Fluorobenzene and Toluene with Oxygen, J. Phys. Chem. A, 1999, 103, 7136-7138.

67 M. L. Chabinyc, S. L. Craig, C. K. Regan and J. I. Brauman, Gas-Phase Ionic Reactions: Dynamics and Mechanism of Nucleophilic Displacements, Science, 1998, 279, 1882-1886.

68 S. Skokov, A. Kazakov and F. L. Dryer, presented in part at the Fourth Joint Meeting of the U.S. Sections of the Combustion Institute, Philadelphia, PA, March 20-23, 2005.

69 C. Barckholtz, M. J. Fadden and C. M. Hadad, Computational Study of the Mechanisms for the Reaction of $\mathrm{O}_{2}\left(3 \sigma_{\mathrm{g}}\right)$ with Aromatic Radicals, J. Phys. Chem. A, 1999, 103, 8108-8117.

70 R. P. Lindstedt and G. Skevis, Detailed Kinetic Modeling of Premixed Benzene Flames, Combust. Flame, 1994, 99, 551-561.

71 N. Sebbar, H. Bockhorn and J. Bozzelli, Thermodynamic Properties of the Species Resulting from the Phenyl Radical with $\mathrm{O}_{2}$ Reaction System, Int. J. Chem. Kinet., 2008, 40, 583-604. 